\title{
Evidencias de canibalización de secuencias Cretácicas y Paleógenas de la Cuenca Oriente en la cuña orogénica de los Andes ecuatorianos
}

\author{
Ana Gramal-Aguilar ${ }^{1 *}\left(\mathbb{D}\right.$; Fausto Carranco-Andino ${ }^{1} \mathbb{D}$; Christian Romero-Cóndor $^{1} \mathbb{D}$; \\ Roberto Pulupa-Vela ${ }^{1}$ [D; Darío Calderón-Romero ${ }^{1}\left[\right.$; Silvia Toainga-Oñate $^{1}$
}

Forma de citar: Gramal-Aguilar, A.; Carranco-Andino, F.; Romero-Cóndor, C.; Pulupa-Vela, R.; CalderónRomero, D.; Toainga-Oñate, S. (2021). Evidencias de canibalización de secuencias Cretácicas y Paleógenas de la Cuenca Oriente en la cuña orogénica de los Andes ecuatorianos. Boletín de Geología, 43(3), 15-34. https://doi.org/10.18273/revbol.v43n3-2021001

Material Suplementario: este artículo tiene Material Suplementario.

\section{Resumen}

Al sureste de la Cordillera Real, en la sección del río Miriumi, rocas sedimentarias e ígneas metamorfoseadas fueron agrupadas sin discriminación en la Unidad Upano, y la falla Palanda-Méndez-Cosanga fue considerada un límite de terreno en anteriores investigaciones. El objetivo de esta investigación es caracterizar y discriminar rocas sedimentarias e ígneas metamorfoseadas de la Unidad Upano, de rocas sedimentarias de la Cuenca Oriente. Esta discriminación está soportada en datos litoestratigráficos, identificación de estructuras sedimentarias, registro de fósiles, estudios petrográficos y análisis de datos estructurales. Rocas meta-volcánicas y meta-pelíticas afloran en la parte occidental de la sección; mientras que hacia el este de la sección, secuencias estratodecrecientes de conglomerados de cuarzo, cuarzo-areniscas, lodolitas y areniscas con estructuras mareales; calizas mudstone y wackstone, lutitas negras con abundantes trazas de amonites y bivalvos son afectadas por un pliegue anticlinal. En el río Upano, calizas y lutitas fosilíferas son cubiertas en discordancia por limolitas multicolores y red beds. Considerando la descripción inicial de la Unidad Upano, se restringe a esta secuencia a rocas meta-volcánicas y meta-pelíticas de bajo grado de metamorfismo en facies de sub-esquistos verdes relacionadas a la dinámica regional. En este estudio, cuarzo-areniscas y lodolitas con estructuras mareales son incluidas en la Formación Hollín, calizas y lutitas con Inoceramus sp. y Harleites sp. (?) son asociadas a la Formación Napo; y secuencias de red beds son vinculadas a la Formación Tena. La presencia de bloques y escamas tectónicas compuestos por las formaciones Hollín, Napo y Tena de la Cuenca Oriente en el frente de la cuña orogénica, afectadas por zonas de corrimiento y pliegues de arrastre indican que la falla Palanda-Méndez-Cosanga, no constituye un límite de terreno entre secuencias metamórficas de la Cordillera Real y secuencias sedimentarias de la Cuenca Oriente. Al contrario, nuestros datos concuerdan con el modelo de canibalización de secuencias de foreland.

Palabras clave: Faja corrida y plegada; Secuencias Cretácicas y Paleógenas; Cuña orogénica; Zona Sub-Andina.

\section{Cannibalization evidences of the Oriente Basin Cretaceous and Paleogene sequences the in the orogenic wedge-top of the Ecuadorian Andes}

\begin{abstract}
To the southeast of the Cordillera Real, on the Miriumi river section, indiscriminated metamorphosed sedimentary and igneous rocks were included in the Upano Unit, as well as the Palanda-Méndez-Cosanga fault which was considered a terrain boundary in previous research. This research aims to characterize and discriminate the Upano Unit metamorphosed sedimentary and igneous rocks from the Oriente Basin sedimentary rocks. This discrimination is supported by lithostratigraphic data, identification of sedimentary structures, the fossil record, petrographic studies, and structural data analysis. Meta-volcanic and meta-pelitic rocks crop out in the western part of the section, whilst eastward in the section, fining-upward succession of quartz-conglomerates, quartz-sandstones, mudstone and sandstone with tidal structures; mudstone and wackstone limestones, black shale with abundant traces of the ammonites and bivalves are deformed by an anticline fold. On the Upano river, limestones and fossiliferous shales are discordantly overlain by multicolored siltstones and red beds. Considering the initial description of the Upano Unit, this sequence is restricted to meta-volcanic and meta-pelitic rocks, suggesting a low metamorphic grade in the sub-green schists facies that relates to the regional geodynamic. In this research, quartz-sandstones and mudstones with tidal signatures are included in the Hollín Formation, limestones and shales with Inoceramus sp. and Harleites sp. (?) are associated with the Napo Formation; and the sequences of red beds are linked to the Tena Formation. The presence of blocks and tectonic slivers conformed by rocks of Hollín, Napo, and Tena formations in the front of the orogenic wedge-top, which are affected by a thrust belt and drag folds, suggests that the Palanda-Méndez-Cosanga fault is not a terrain boundary between metamorphic sequences of the Cordillera Real and sedimentary sequences of the Oriente Basin. On the contrary, our data agree with the cannibalization model of foreland sequences.
\end{abstract}

Keywords: Thrust belt; Cretaceous and Paleogene sequences; Wedge-top; Sub-Andean Zone.

${ }^{1}$ Instituto de Investigación Geológico y Energético, Quito, Ecuador. $(*)$ ana.gramal@geoenergia.gob.ec, fausto.carranco@geoenergia.gob.ec,wladimir.romero@geoenergia.gob.ec, anibal.pulupa@geoenergia.gob.ec, dario.calderon@geoenergia.gob.ec, silvia.toainga@geoenergia.gob.ec 


\section{Introducción}

El principal accidente morfológico de la margen noroeste sudamericana es los Andes del Norte, que en Ecuador mantiene una tendencia norte-sur e incluye dos cordilleras genéticamente distintas: la Cordillera Occidental, que se compone de rocas volcánicas máficas e intermedias y rocas intrusivas yuxtapuestas, principalmente con depósitos turbidíticos de edad Cretácico tardío a Oligoceno (Vallejo et al., 2009, 2019; Jaillard et al., 2009); y la Cordillera Real, que representa un núcleo de rocas metamórficas paleozoicas y granitos mesozoicos exhumados (Litherland et al., 1994; Spikings et al., 2015). Estas cordilleras están separadas por el valle Interandino que guarda el registro del volcanismo cuaternario, limitado al oeste por la falla Calacalí-Pujilí-Pallatanga (FCPP en Figura 1) y al este por la falla Peltetec (FP en Figura 1) (Litherland et al., 1994). El sistema de fallas PalandaMéndez-Cosanga (FPMC en Figura 1) representa el límite este de la Cordillera Real; al este de la FPMC se encuentra la Zona Sub-Andina (ZSA en Figura 1), la cual constituye el wedge-top andino, es decir, un cinturón deformado y exhumado, que registra el levantamiento de los Andes y su avance hacia el este en un sistema de cuenca de antepaís. Las rocas expuestas en la ZSA a su vez proporcionan información sobre las diversas secuencias sedimentarias de la Cuenca Oriente. La complejidad de la ZSA está relacionada con la propagación del frente orogénico sobre un sustrato heterogéneo heredado de paleogeografías preandinas (Ruiz et al., 2004; Baby et al., 2013).

Con respecto a la estructura de la ZSA, Dashwood y Abbotts (1990), Balkwill et al. (1995) y Barragán et al. (2005) proponen la presencia de una cuña orogénica de empuje, resultado de un complejo basamento sometido a diferentes periodos de deformación. Ruiz et al. (2007) indican que la ZSA se encuentra subdividida en dos zonas: una interior o proximal de muy alta deformación, que se caracteriza por la presencia de escamas tectónicas al oeste de la FPMC, y una zona exterior con estructuras de menor grado de deformación, en la cual predominan sistemas de cabalgamiento (levantamiento Napo al norte y levantamiento Cutucú al sur). Mediante secciones sísmicas, Baby et al. (2013) señalan que la deformación de la Cuenca Oriente se origina por un sistema de empuje de tipo piel gruesa, que se extiende desde la Cordillera Real hasta la falla Tiputini Oriental, que estaría relacionado con una zona de desprendimiento intrabasamento que se profundiza en la ZSA. Dentro de este contexto, la ZSA representa el frente de la faja de plegamiento y cabalgamiento, es decir, una zona de transición entre la Cordillera Real y la Cuenca Oriente, que involucra fragmentos canibalizados de la margen continental incorporados a la orogenia (Gutiérrez et al., 2019).

En el límite entre la Cordillera Real y la ZSA, anteriores investigaciones reportaron de manera regional la presencia de rocas meta-sedimentarias indiscriminadas y asociadas a la Unidad Upano del Terreno Salado (INEMIN, 1990; BGS-CODIGEM, 1994). En la vía desde Santiago de Méndez a Patuca, en el levantamiento Cutucú, Jaillard et al. (1997) sugieren que secuencias meta-sedimentarias podrían estar vinculadas genéticamente con rocas cretácicas de la Cuenca Oriente. Mientras que, en el trayecto de Baños a Puyo, Pratt et al. (2005) agrupan las rocas meta-sedimentarias en la Formación Margajitas, como un equivalente relativamente condensado de la secuencia Cretácica de la Cuenca Oriente, marcando un depocentro sedimentario en la ZSA, controlado por la subsidencia hacia el oeste bajo la FPMC. Sin embargo, en ninguna de estas campañas de cartografía geológica dichas secuencias fueron caracterizadas, por tanto, se desconoce la litoestratigrafía, el detalle petrográfico y los estilos de deformación de estas secuencias.

La FPMC representa el límite este de la División Salado de la Cordillera Real (Aspden y Litherland, 1992; Litherland et al., 1994) y el límite oeste de las secuencias sedimentarias de la Cuenca Oriente, expuestas en la ZSA. Sin embargo, en recientes campañas de cartografía geológica (IIGE, 2019), en el suroeste de la Cordillera Real, se documentó la presencia de areniscas y lutitas potencialmente asociadas a las formaciones Hollín y Napo al oeste de la FPMC (Figura 2).

Esta investigación presenta el detalle litoestratigráfico de la sección del río Miriumi (Figura 1), localizada al oeste de Sucúa (UTM: A: 803 732E, 9735 456N; B: 819 925E, 9 $728111 \mathrm{~N})$. Esta sección no ha sido reportada previamente, y tampoco ha sido incluida en el contexto geológico regional. En este trabajo se documentan estructuras sedimentarias y relictos de estructuras sedimentarias en rocas meta-sedimentarias, además, se presenta la caracterización petrográfica y el estilo de deformación de las secuencias Cretácicas y Paleógenas: Unidad Upano, Formación Hollín, Formación Napo y Formación Tena. Este trabajo presenta características físicas útiles en la identificación y discriminación en campo de secuencias sedimentarias, así como su deformación. 


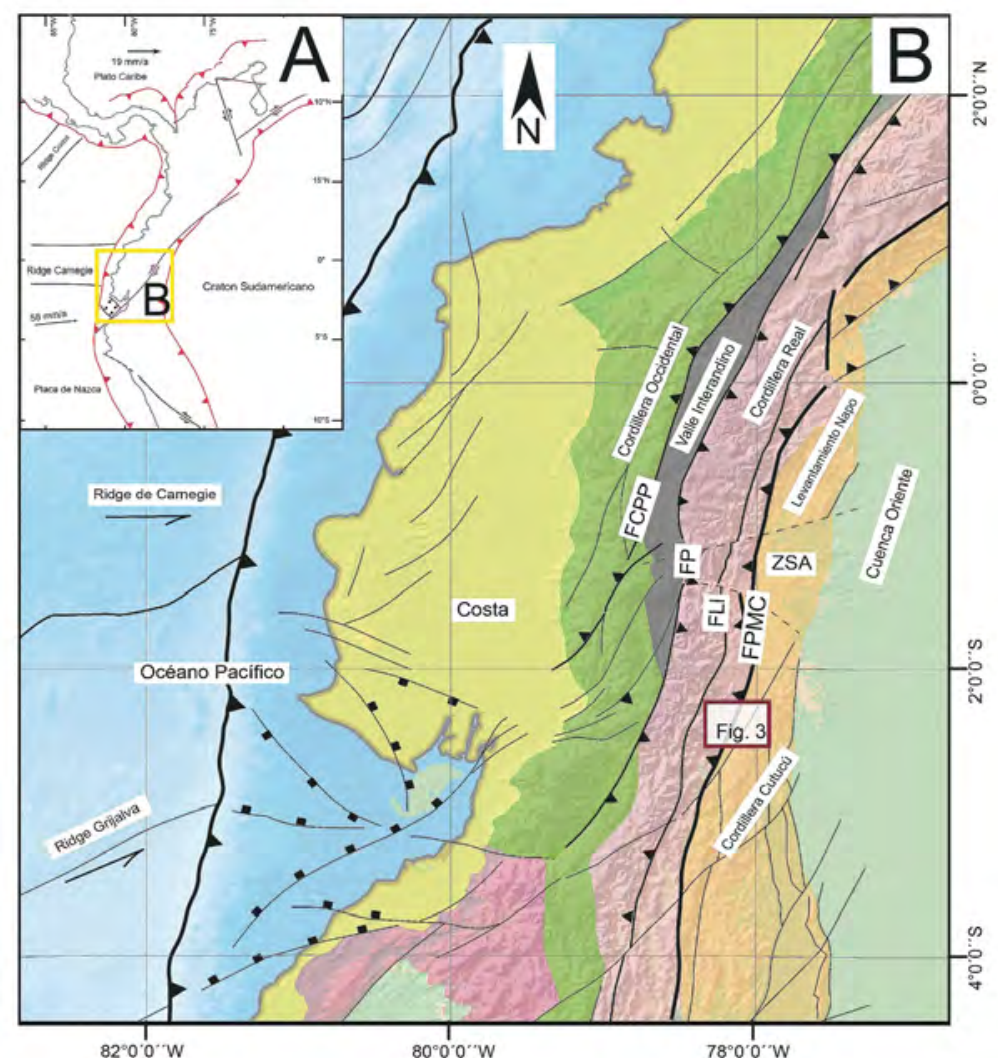

Figura 1. Mapa morfo-tectónico del Ecuador. A. Esquema tectónico de la margen noroeste sudamericana. B. Ubicación del área de estudio en el mapa morfo-tectónico del Ecuador. FCPP: falla Calacalí-Pujilí-Pallatanga; FP: falla Peltetec; FPMC: falla Palanda-Méndez-Cosanga. Modificado de BGS-CODIGEM (1994), INIGEMM (2017) y Vallejo et al. (2019).

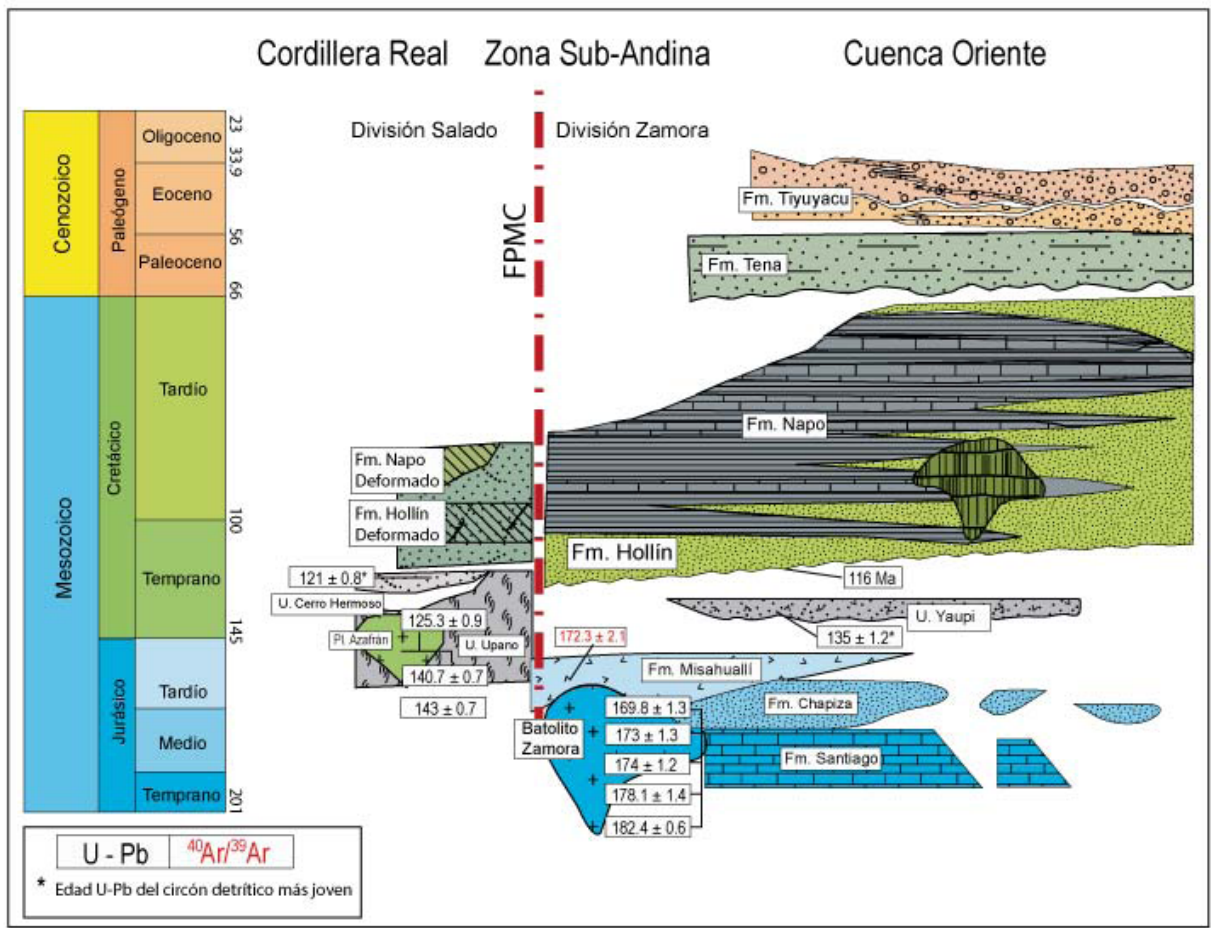

Figura 2. Esquema litoestratigráfico del sur de la Zona Sub-Andina. Modificado de Gutiérrez et al. (2019). 


\section{Contexto geológico regional}

\section{Cordillera Real}

La Cordillera Real contiene rocas sedimentarias e ígneas metamorfoseadas del Paleozoico al Cretácico temprano, y quizás más antiguas (Spikings et al., 2021). Aspden y Litherland (1992) discriminan en divisiones tectono-estratigráficas las secuencias metamórficas de la Cordillera Real; de oeste a este, son: Guamote, Alao, Loja, Salado y Zamora. La División Salado limita al oeste con la falla Llanganates y al este con la FPMC (Figura 1), incluye rocas meta-volcánicas y meta-sedimentarias de las unidades Upano, Cuyuja y Cerro Hermoso (Figura 2), depositadas en una cuenca marginal desarrollada en el intervalo Jurásico superior a Cretácico inferior (Litherland et al., 1994; Spikings et al., 2015).

La Unidad Upano agrupa rocas verdes andesíticas, meta-lavas, meta-brechas, filitas, esquistos verdes, esquistos grafíticos, meta-areniscas, meta-pelitas y meta-grawacas (Litherland et al., 1994). Spikings et al. (2015) reportan edades $\mathrm{U} / \mathrm{Pb}$ en circones detríticos de $143,3 \pm 9,9$ Ma en la Unidad Upano, mientras que Pratt et al. (2005) en función de relaciones estratigráficas indican que la Unidad Upano fue afectada por la intrusión del batolito de Azafrán (Figura 2), el cual incluye a dioritas hornbléndicas, granitos y granitoides deformados, datados a 143 \pm 1 Ma (Spikings et al., 2001).

\section{Zona Sub-Andina (ZSA)}

Hacia el sur de la ZSA, el basamento de la Cordillera Cutucú está compuesto por cuarcitas y filitas de la Formación Pumbuiza, así como por calizas fosilíferas, areniscas calcáreas y lutitas de la Formación Macuma (Tschopp, 1953). En discordancia con el basamento, se deposita la Formación Santiago, que se compone de calizas, lutitas fosilíferas, areniscas calcáreas y niveles volcánicos (Tschopp, 1953) con abundantes trazas de amonites del Jurásico inferior (Gaibor et al., 2008). La Formación Santiago está cubierta en discordancia por múltiples secuencias de red beds de la Formación Chapiza (Tschopp, 1953). Según Litherland et al. (1994) la Formación Misahuallí representa la expresión volcánica de intrusiones jurásicas y se compone de andesitas, riolitas y brechas volcánicas (Figura 2).

La Formación Hollín se desarrolla en discordancia angular sobre un relieve litológicamente heterogéneo, deformado y peneplanizado (Figura 2). En la base de la Formación Hollín se observan conglomerados de cuarzo y cuarzo-areniscas, mientras que hacia el tope de la secuencia se observan intercalaciones rítmicas de areniscas y lutitas, con estructuras de marea (White et al., 1995; Romero, 2018). El contacto con la Formación Napo está marcado por la presencia de glauconita y extensos niveles con bioturbación (Jaillard et al., 1997; Romero, 2018). La Formación Napo sobreyace a la Formación Hollín y se compone de potentes paquetes de lutitas calcáreas fosilíferas, intercaladas con niveles de areniscas de cuarzo y areniscas glauconíticas, depositadas en respuesta a variaciones del nivel del mar durante el Cretácico (Vallejo et al., 2021). Niveles de caliza tipo mudstone y wackstone son comunes en la parte media y superior de la Formación Napo. Depósitos continentales de la Formación Tena del Mastrichtiano a Paleoceno (Jaillard et al., 1997) cubren en inconformidad a la Formación Napo (Figura 2).

\section{Metodología}

En campo, la cartografía geológica se enfocó en la discriminación litológica a partir de la caracterización mineralógica, la descripción de la textura de las rocas, la identificación de estructuras sedimentarias y relictos de estructuras sedimentarias, la asociación de facies, la medición de espesores, la documentación de superficies de erosión, la recopilación de datos estructurales y el análisis litoestratigráfico. La discriminación de secuencias sedimentarias fue realizada a partir del concepto de "facies", definido por Walker (1990) como un cuerpo de roca caracterizado por una particular combinación de litologías, estructuras físicas y biológicas que le confieren un aspecto diferente a los cuerpos de rocas adyacentes dentro de una secuencia continua. En lo posterior, se utilizó el concepto de "asociación de facies" empleando la metodología descrita a detalle por James y Dalrymple (2010), con el fin de agrupar facies genéticamente relacionadas con un mismo ambiente de depósito.

A partir de la fotointerpretación de imágenes satelitales de alta resolución, se realizó el análisis estructural, con el fin de complementar la cartografía geológica en la zona de estudio (INEMIN, 1990; BGSCODIGEM, 1994; IIGE, 2019); de esta manera, se filtraron lineamientos de la cartografía regional y se redefinieron trazos de las fallas geológicas presentes en el área. Con respecto al levantamiento de datos estructurales en campo, se reconoció la vergencia de las estructuras plegadas y falladas según su geometría y el desplazamiento en distintos sectores del área de trabajo. El análisis cinemático está sustentado en la 
medición y procesamiento de 197 planos estriados de fallas, diaclasas y estratificación. Los datos fueron recolectados en 121 afloramientos de la Unidad Upano y las formaciones Hollín, Napo y Tena.

Los datos incluyeron rumbo, buzamiento y estratificación (Material Suplementario). En el análisis de la cinemática de cada estructura (falla, pliegue y diaclasa) se consideraron los indicadores descritos a detalle por Petit (1987).

\section{Resultados}

\section{Litoestratigrafía}

4.1.1 Unidad Upano $\left(\boldsymbol{J}_{s u}\right)$ : al oeste de la FPMC aflora la Unidad Upano en forma de escamas y franjas tectónicas limitadas por fallas de rumbo nortenoreste, de alto ángulo (Figura 3), compuestas por facies meta-volcánicas (FMv) y facies meta-pelíticas (FMp). La parte inferior de la secuencia se compone de apilaciones verticales de estratos diaclasados de 20 m a 30 m (Figura 4; Figura 5A), compuestos por metaandesitas porfiríticas, con plagioclasa $(38 \%)$, epidota $(28 \%)$, clorita $(18 \%)$, hornblenda $(16 \%) \pm$ sericita
$(<10 \%)$ de grano fino a medio (Figura 5C-5D) y rocas verdes masivas con clorita $(30 \%)$, epidota $(25 \%)$, plagioclasa $(15 \%) \pm$ sericita $(<10 \%) \pm$ cuarzo $(<5 \%)$ (FMv en Tabla 1; Figura 4). En menor proporción, se observan meta-brechas silicificadas, con fragmentos deformados de andesitas, rocas verdes y filitas; en la matriz se tienen altas proporciones de clorita $(35 \%)$ y sericita (30\%), con diseminación de sulfuros $(<10 \%)$. También se observan fragmentos deformados y estructuras de reemplazamiento, calcita \pm epidota que reemplaza a la hornblenda.

La parte superior de la Unidad Upano aflora al oeste de la falla A y al este de la falla F (Figura 3), consiste en paquetes inclinados con geometría tabular, lateralmente continuos de $1 \mathrm{~m}$ a $3 \mathrm{~m}$ (Figura 4; Figura $5 \mathrm{~B})$, de esquistos de color gris a verde con clorita $(30 \%)$, minerales arcillosos $(30 \%)$, cuarzo $(20 \%)$, moscovita $(10 \%) \pm$ sericita $(<10 \%)($ FMp en Tabla 1 ; Figura 4; Figuras 5E-5F); también es común observar esquistos de illita $(60 \%)$, calcita $(30 \%) \pm$ sericita $(<10 \%)$ (Figura $5 \mathrm{G}-5 \mathrm{H})$ y esquistos sericíticos. En menor proporción, se observan pizarras negras y filitas con abundante grafito intercaladas entre las facies de meta-pelitas (FMp en Tabla 1; Figura 4).

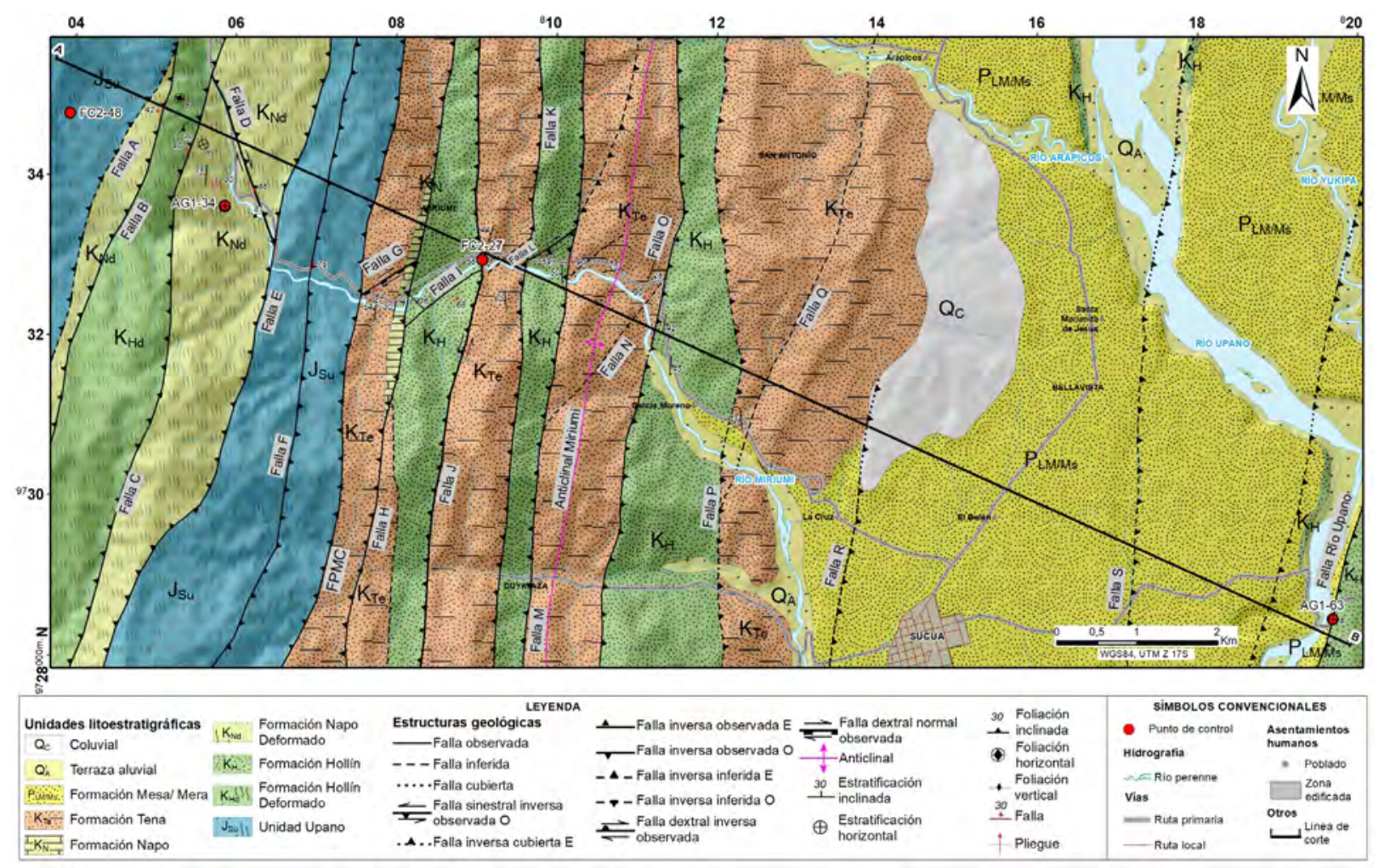

Figura 3. Mapa geológico de la sección del río Miriumi, Sucúa-Ecuador. Modificado de IIGE (2019). 
Tabla 1. Resumen de facies documentadas en las unidades y formaciones en la sección del río Miriumi.

\begin{tabular}{|c|c|c|c|c|}
\hline Fm & Facies & Litología - estructuras sedimentarias & Interpret: & ación \\
\hline \multirow{7}{*}{ 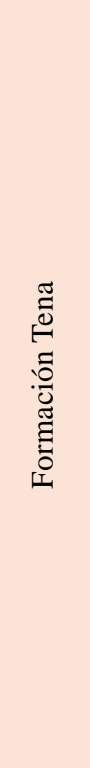 } & AGG & $\begin{array}{l}\text { Arenisca gris con tonalidad rojiza, de grano } \\
\text { grueso a muy fino, bien sorteada, con gradación } \\
\text { normal }\end{array}$ & \multirow{3}{*}{\multicolumn{2}{|c|}{ Barras de punto (point bar) }} \\
\hline & AGXP & $\begin{array}{l}\text { Arenisca gris con tonalidad rojiza, de grano } \\
\text { grueso a muy fino, con estratificación cruzada } \\
\text { paralela }\end{array}$ & & \\
\hline & AGXT & $\begin{array}{l}\text { Arenisca gris con tonalidad rojiza, de grano } \\
\text { grueso a muy fino, con estratificación cruzada } \\
\text { transversal }\end{array}$ & & \\
\hline & LAM & $\begin{array}{l}\text { Limolitas arenosas (red beds) con gradación } \\
\text { normal }\end{array}$ & \multirow{4}{*}{\multicolumn{2}{|c|}{ Planicies de inundación }} \\
\hline & LAR & Limolitas arenosas (red beds) con ripples & & \\
\hline & LAMC & $\begin{array}{l}\text { Limolitas arenosas masivas con niveles } \\
\text { calcáreos }\end{array}$ & & \\
\hline & LL & $\begin{array}{l}\text { Limolitas laminadas color gris oscuro con } \\
\text { estratificación cruzada paralela, con gradación } \\
\text { normal }\end{array}$ & & \\
\hline \multirow{4}{*}{ 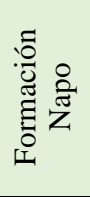 } & \multirow{4}{*}{$\begin{array}{c}\text { LC } \\
\text { LGF } \\
\text { CM } \\
\text { CW-CP }\end{array}$} & Lutitas calcáreas fosilíferas & \multirow{4}{*}{\multicolumn{2}{|c|}{ Plataforma marina somera }} \\
\hline & & Lutitas glauconíticas con fósiles & & \\
\hline & & Calizas negras masivas & & \\
\hline & & Calizas wackstone, packstone & & \\
\hline \multirow{9}{*}{ 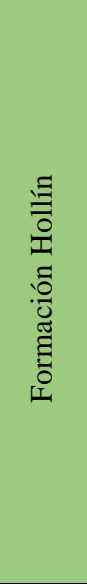 } & IAL & $\begin{array}{l}\text { Intercalaciones rítmicas de areniscas y lodolitas } \\
\text { con carbón }\end{array}$ & \multirow{5}{*}{\multicolumn{2}{|c|}{ Ambientes costeros con influencia de mareas }} \\
\hline & ALF & Areniscas con laminación flaser & & \\
\hline & ALO & Areniscas con laminación ondulítica & & \\
\hline & ALL & Areniscas limosas con laminación lenticular & & \\
\hline & ARB & Areniscas finas con ripples bidireccionales & & \\
\hline & Gmg, & Conglomerados de cuarzo gradados & \multirow{4}{*}{\multicolumn{2}{|c|}{ Barras fluviales de ríos trenzados }} \\
\hline & $\xi$ & $\begin{array}{l}\text { Cuarzo-areniscas gruesas a medias con } \\
\text { estratificación cruzada transversal }\end{array}$ & & \\
\hline & Sp, & $\begin{array}{l}\text { Cuarzo-areniscas medias a finas, con } \\
\text { estratificación cruzada paralela }\end{array}$ & & \\
\hline & Sm & Areniscas finas masivas & & \\
\hline $\mathbf{U}$ & Facies & Litología & Protolito & $\begin{array}{l}\text { Facies } \\
\text { metamórficas }\end{array}$ \\
\hline \multirow{2}{*}{ 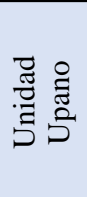 } & FMp & $\begin{array}{l}\text { Esquistos de clorita, esquistos cálcicos, pizarras } \\
\text { y filitas con grafito }\end{array}$ & $\begin{array}{l}\text { Argilitas arenosas con } \\
\text { abundante } \\
\text { orgánica }\end{array}$ & \multirow{2}{*}{$\begin{array}{l}\text { Facies de } \\
\text { sub-esquistos verdes }\end{array}$} \\
\hline & FMv & Meta-andesitas, rocas verdes, meta-brechas & $\begin{array}{l}\text { Secuencias de arco } \\
\text { volcánico }\end{array}$ & \\
\hline
\end{tabular}




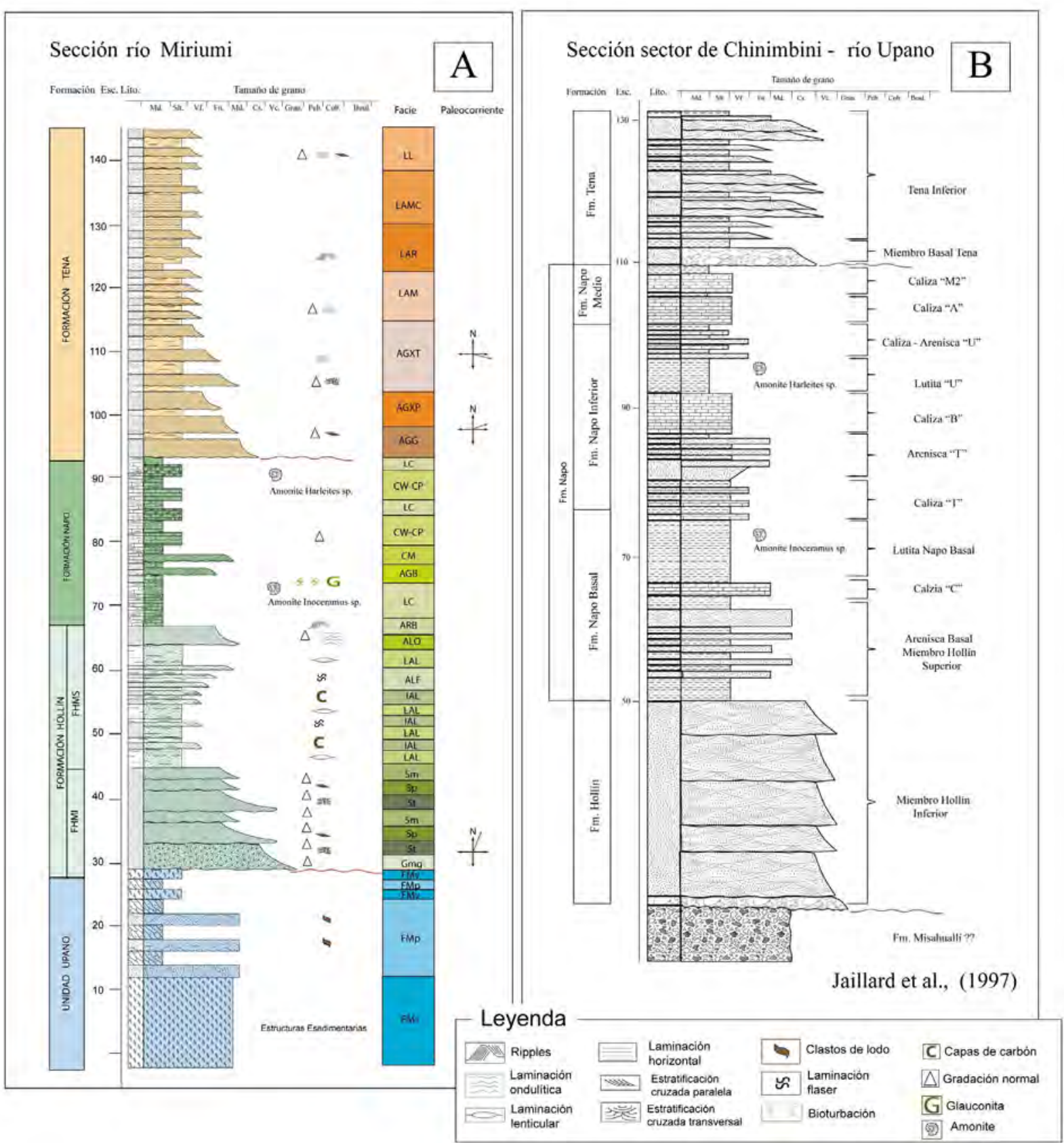

Figura 4. Columna estratigráfica de la zona de estudio. A. Sección río Miriumi levantada en el presente estudio. B. Sección Chinimbini - río Upano, ubicada al sur de la zona de estudio tomado de Jaillard et al. (1997).

Formación Hollín $\left(\boldsymbol{K}_{\boldsymbol{H}}\right)$ : en la margen este del río Upano, la Formación Hollín descansa en discordancia angular sobre la Formación Misahuallí, y la Formación Chapiza, en la margen norte del río Miriumi, cubre en discordancia a la Unidad Upano (Figura 4). El miembro inferior de la Formación Hollín (FHMI en Tabla 1) agrupa secuencias estratodecrecientes con estratos de geometría cóncava-convexa a tabular, lateralmente continuos de conglomerados con matriz- soportada (Figura 6A), monomícticos, con clastos bien redondeados de cuarzo y gradación normal (Gmg en Tabla 1, Figura 4). El miembro inferior de la Formación Hollín también incluye cuarzo-areniscas de grano grueso a medio, bien sorteadas, con gradación normal, estratificación cruzada transversal (St en Tabla 1) y paralela (Sp en Tabla 1, Figura 4, Figura 6B). En el tope del miembro inferior se observan areniscas de grano fino a muy fino, muy bien sorteadas, con 
estratificación cruzada, ripples de corriente y niveles masivos (Sm en Tabla 1, Figura 4). La mineralogía de estas facies está dominada por cuarzo $(>95 \%)$, con bajas proporciones de moscovita $(<5 \%)$ e illita $(<2 \%)$. El espesor observado en campo del miembro inferior alcanza los $20 \mathrm{~m}$ en la margen norte del río Miriumi; mientras que su espesor en la margen oeste del río Upano alcanza los $50 \mathrm{~m}$. Las direcciones de paleocorrientes indican transporte de sedimento hacia el noreste (Figura 4).
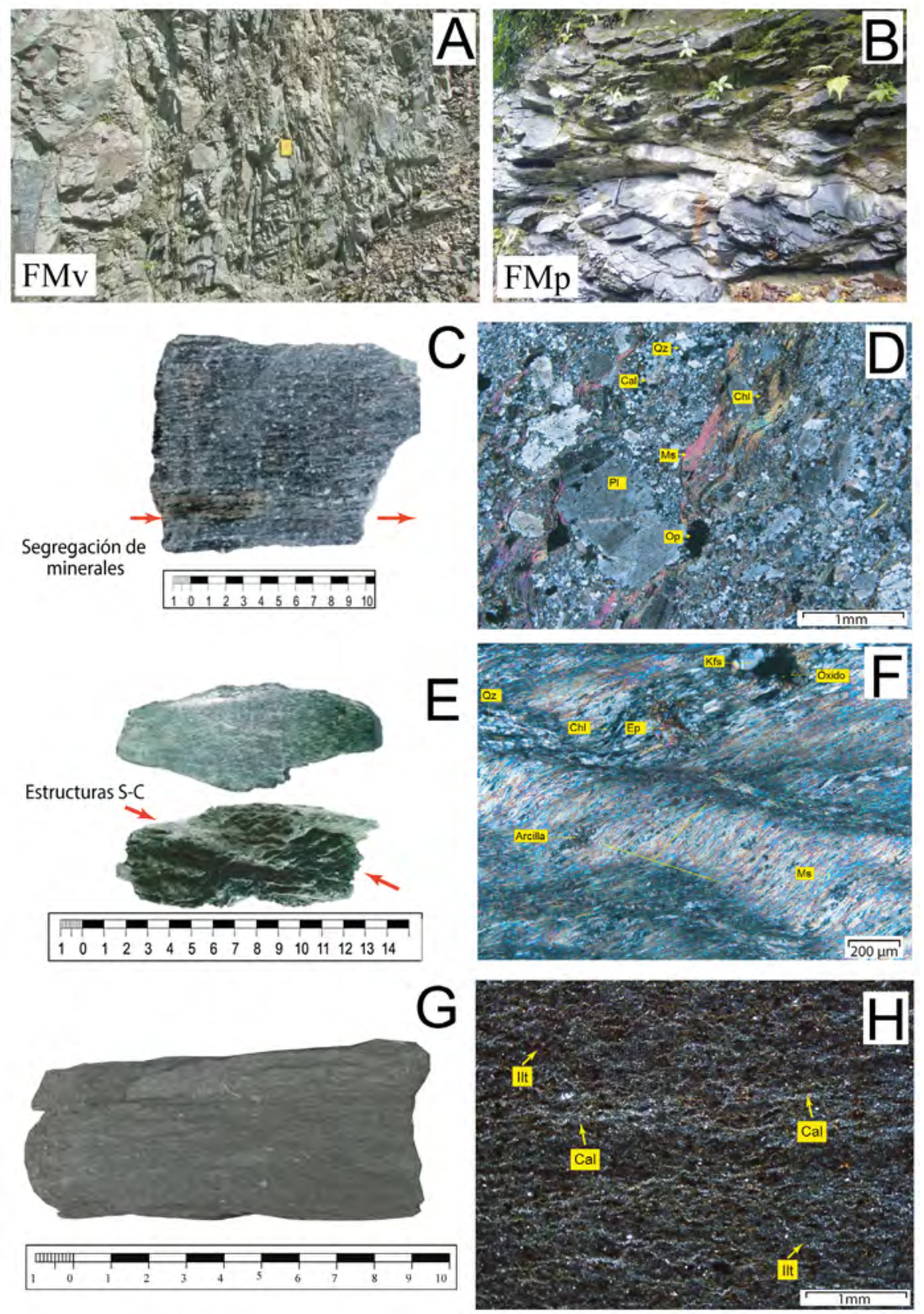

Figura 5. Afloramiento tipo y litofacies de la Unidad Upano. A. Secuencia de rocas meta-volcánicas. B. Secuencias de rocas meta-pelíticas. C. Meta-andesita con segregación de minerales. D. Sección delgada de meta-andesita en luz polarizada. E. Esquisto con estructuras S-C. F. Sección delgada de esquisto en luz polarizada G. Esquisto pelítico. H. Sección delgada de esquisto pelítico en luz polarizada. 
En las cercanías del poblado García Moreno, el miembro superior de la Formación Hollín (FHMS) se deposita localmente en onlap sobre el miembro inferior de la Formación Hollín, e incluye secuencias de estratos de geometría tabular, lateralmente continuos, compuestos por intercalaciones rítmicas de areniscas (IAL en Tabla 1, Figura 4; Figura 6C) de grano fino a muy fino, con laminación flaser (ALF en Tabla 1, Figura 4, Figuras 6D-6F-6G), ondulítica (ALO en Tabla 1, Figura 4; Figuras 6E), ripples bidireccionales (ARB en Tabla 1, Figura 4), superficies de reactivación, areniscas limosas con laminación lenticular (ALL en Tabla 1, Figura 4) y carbón (Figura 4). También se observan estratos de lodolitas masivas con restos de raíces y carbón, con buena continuidad lateral y geometría mantiforme de $50 \mathrm{~cm}$ a $2 \mathrm{~m}$ (Figuras 6D). La mineralogía de estas facies está dominada por cuarzo (65\%); en menor proporción se observan illita (15\%), carbón (10\%) y moscovita $(10 \%)$. En las proximidades al río Upano, el miembro superior presenta espesores cercanos a los $40 \mathrm{~m}$, mientras que en las cabeceras del río Miriumi, su espesor no supera los $20 \mathrm{~m}$ (Figura 4).
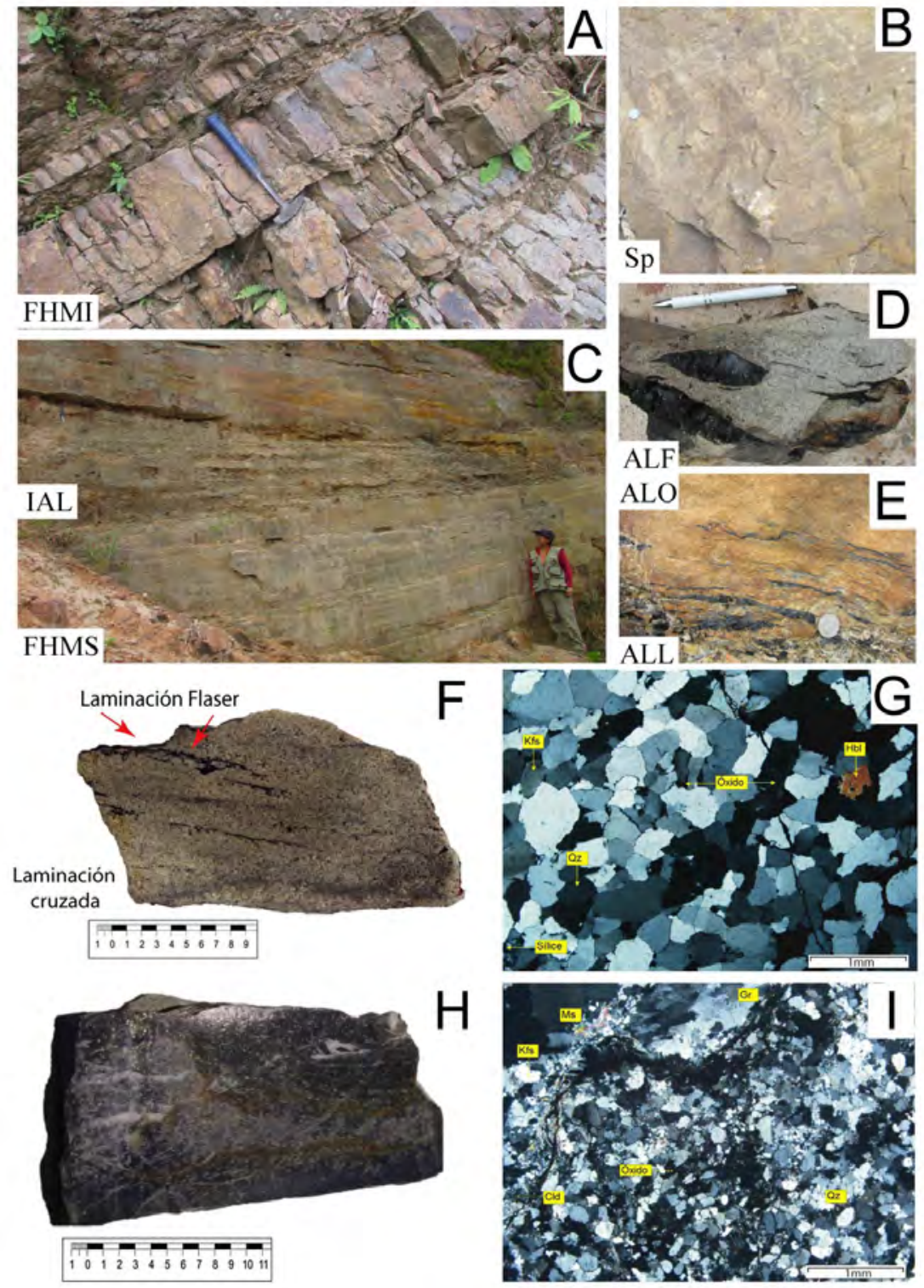

Figura 6. Afloramiento tipo y litofacies de la Formación Hollín. A. Miembro inferior de la Formación Hollín. B. Arenisca gruesa con estratificación cruzada paralela. C. Miembro superior de la Formación Hollín. D. Arenisca fina con laminación flaser y lentes de carbón. E. Arenisca fina con laminación flaser, ondulítica y lenticular. F. Arenisca con laminación cruzada y laminación flaser. G. Sección delgada de arenisca en luz polarizada. H. Meta-arenisca con relictos de laminación cruzada y flaser. I. Sección delgada de meta-arenisca en luz polarizada. 
Facies deformadas de la Formación Hollín $\left(\mathrm{K}_{\mathrm{HD}}\right)$ afloran en forma de ventanas tectónicas, en zonas próximas a las fallas B y C (Figura 3); estas pueden ser observadas en continuidad a secciones no deformadas. Asimismo, se observan facies plegadas en el núcleo aflorante del pliegue anticlinal de Miriumi. Se documentaron secuencias métricas de $1 \mathrm{~m}$ a $3 \mathrm{~m}$, inclinadas a subverticales de $50^{\circ}$ a $80^{\circ}$ de metaareniscas y cuarcitas de grano grueso a fino, facies heterolíticas, finas intercalaciones rítmicas de cuarcitas y pizarras, con abundantes figuras ondulíticas. También se observan relictos de estructuras sedimentarias tipo laminación flaser y ondulitas, fragmentos de carbón e intervalos masivos sin estructura (Figuras 6H-6I).

Al sur del área de estudio, en las inmediaciones de Copal (UTM: 787 621E; 9695 975N), se reconocen geometrías de barras mareales deformadas; en este sector se observaron cuarcitas masivas de grano fino a medio, intercalaciones con meta-areniscas y filitas con relictos de estructuras de marea: laminación ondulítica, ripples bidireccionales y superficies de reactivación. La mineralogía de estas facies está dominada por cuarzo $(75 \%)$, sericita $(15 \%) \mathrm{y}$, en menor proporción $(10 \%)$, por moscovita, illita y grafito (Figura 6I).

Formación Napo $\left(K_{N}\right)$ : aflora en las inmediaciones del poblado Miriumi, en forma de franjas aisladas de dirección noreste-suroeste, estratigráficamente limitada por la presencia de la Formación Tena hacia las partes altas (Figura 3). Agrupa secuencias estratificadas de lutitas negras con cementación calcárea (LC en Tabla 1, Figura 4, Figura 7A), niveles de calizas negras masivas (CM en Tabla 1, Figura 4; Figura 7A), calizas de textura wackstone y packstone (CW-CP en Tabla 1, Figura 4; Figura 7B-7C) y lutitas glauconíticas bioturbadas con improntas de amonites (LGF en Tabla 1, Figura 4; Figura 7D). Al oeste de Miriumi se documentaron lutitas laminadas con abundantes bivalvos y gasterópodos, incluyendo el bivalvo Inoceramus sp. y el amonite Harleites sp. (?). El espesor de la Formación Napo en el río Miriumi no supera los $30 \mathrm{~m}$, mientras que en la margen oeste del río Upano el espesor de la Formación Napo alcanza 60 m (Figura 4).

En las cercanías a Miriumi, así como en las proximidades a las fallas A, B, C, D y E, se observan facies plegadas y deformadas de la Formación Napo $\left(\mathrm{K}_{\mathrm{ND}}\right)$ (Figura 3), que incluyen intercalaciones entre lutitas negras con cementación calcárea, filitas negras y pizarras. También es frecuente la presencia de calizas grises masivas y calizas recristalizadas. Se observan ocasionalmente fragmentos de bivalvos Inoceramus sp., gasterópodos, amonites deformados e improntas de fósiles no identificados en niveles de meta-lutitas (Figura 7E). La mineralogía de las facies de lutitas, pizarras y filitas (Figura 6G) está dominada por la presencia de illita, calcita \pm sericita (Figura 7F-7H), mientras que en calizas recristalizadas es frecuente la presencia de calcita \pm dolomita.

Formación Tena $\left(K_{T e}\right)$ : aflora en los flancos del pliegue anticlinal de Miriumi, en forma de bloques tectónicos erosionados con capas inclinadas a subverticales de $50^{\circ}$ a $70^{\circ}$ (Figura 3). La Formación Tena cubre en inconformidad a la Formación Napo (Figura 8A) e incluye apilaciones verticales de $2 \mathrm{~m}$ a $10 \mathrm{~m}$ de secuencias estratodecrecientes con geometría cóncava a convexa discontinuas (Figura 8B), conformadas por areniscas de grano muy grueso a medio, con gradación normal (AGG en Tabla 1, Figura 4), estratificación cruzada transversal (AGXT en Tabla 1, Figura 4) y paralela (AGXP en Tabla 1, Figura 4, Figura 8B). En menor proporción, se observan estratos de geometría tabular continua, de areniscas finas y limolitas arenosas con laminación paralela y niveles masivos, con abundantes clastos de lodolitas y materia orgánica (Figura 8C). Las direcciones de paleocorrientes indican transporte de sedimento hacia el este (Figura 4).

La parte media y superior de la secuencia se caracteriza por la presencia de estratos métricos de $1 \mathrm{~m}$ a $3 \mathrm{~m}$, tabulares y mantiformes, lateralmente continuos de limolitas arenosas masivas de color rojo a violeta (LAM en Tabla 1, Figura 4 y Figura 8D), con laminación paralela (LL en Tabla 1, Figura 4 y Figura 8D), abundantes niveles masivos con materia orgánica (LAMC en Tabla 1, Figura 4 y Figura 8E) y ripples de corriente (LAR en Tabla 1, Figura 4 y Figura 8F). También se observan en esta parte de la secuencia estratos canalizados de areniscas de grano medio a fino, con estratificación cruzada (AGXT en Tabla 1, Figura 4), gradación normal (AGG en Tabla 1, Figura 4) y fragmentos de limolitas rojas. Secciones delgadas de areniscas de la Formación Tena muestran textura psamítica de grano medio a grueso, composición oligomíctica, con cristales subangulares a subredondeados de cuarzo $(60 \%)$ y plagioclasa $(10 \%)$, con proporciones relativas de minerales opacos (Figura 8G). Las limolitas arenosas con cemento ferruginoso muestran cristales de cuarzo, plagioclasa y abundantes óxidos de hierro (Figura 8H). El espesor de la Formación Tena observado en las proximidades a Miriumi corresponde a $65 \mathrm{~m}$, y en las márgenes del río Upano su espesor disminuye a menos de 20 m (Figura 4). 

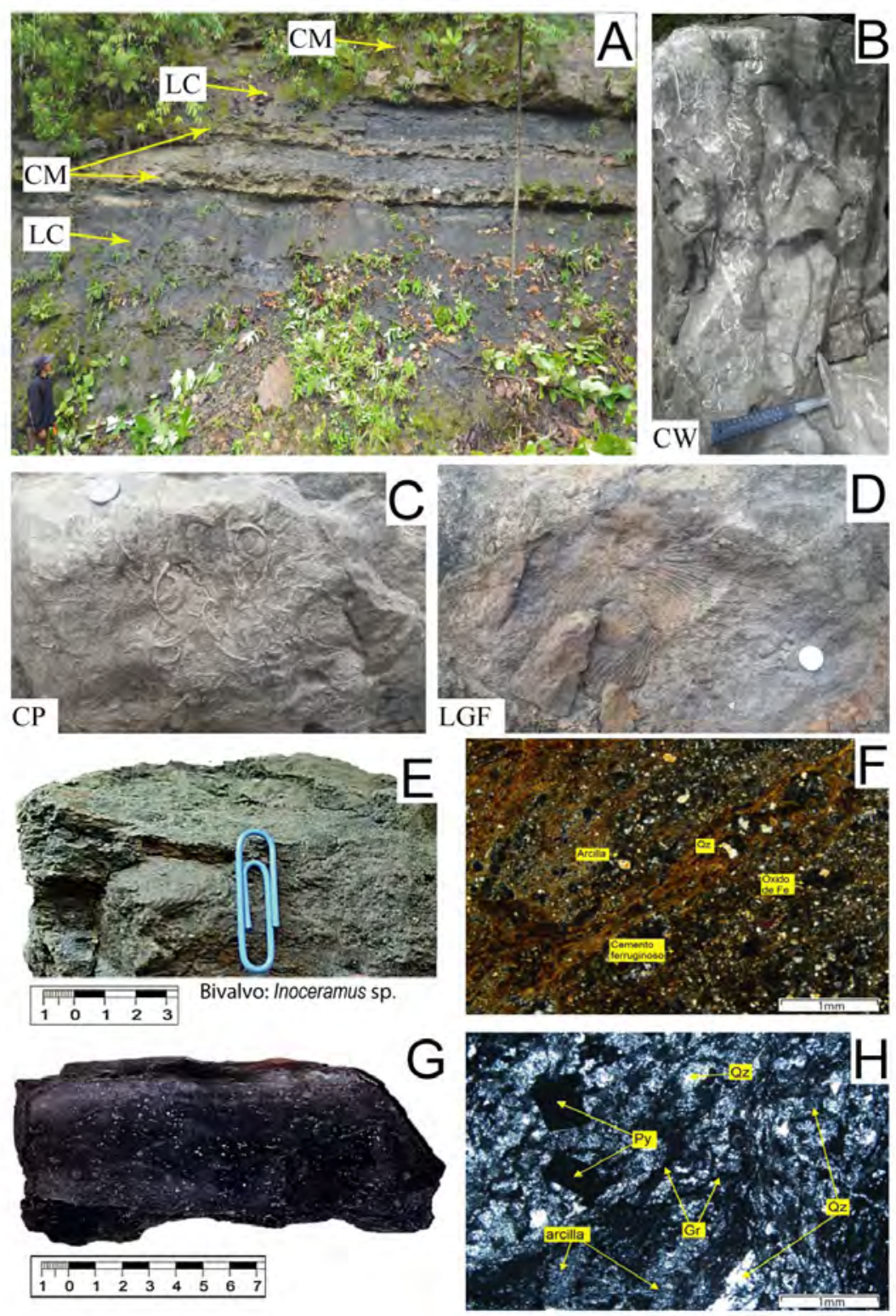

Figura 7. Afloramiento tipo y litofacies de la Formación Napo. A. Intercalación de lutitas calcáreas y calizas masivas. B. Calizas de textura wackstone. C. Calizas de textura packstone. D. Impronta de amonite Harleites sp. (?) en lutitas glauconíticas. E. Resto de bivalvo Inoceramus sp. en arenisca limosa glauconítica. F. Sección delgada de lutita limosa en luz polarizada. G. Meta-pelita. H. Sección delgada de meta-pelita en luz polarizada.

\section{Geología estructural}

La zona de estudio fue interpretada en el corte geológico-estructural "A-B" de dirección noroeste a sureste, comprendida desde el sector de los Altos del río Miriumi, en las estribaciones orientales de la Cordillera Real, hasta el margen este del río Upano en Sucúa, correspondiente a la ZSA (Figura 3). Las principales estructuras comprenden un sistema de fallas de rumbo andino casi norte-sur que forma fajas longitudinales paralelas. El perfil geológico estructural
“A-B" se caracteriza por el desarrollo de tres estilos de deformación, descritos a continuación.

Zona corrida. Presenta el grado más alto de deformación observado en la sección, compuesta por rocas de la Unidad Upano, cuñas aisladas y bloques deformados discontinuos de las formaciones Hollín y Napo, limitada al este por la FPMC (Figura 3, Figura 9). Internamente, se observan cuñas o astillas tectónicas de corrimiento asociadas a las fallas A, B, C, 
E y FPMC (Figura 9), que presentan tendencia definida de nor-noreste a sur-suroeste (rumbo andino) con vergencia hacia el oeste formando ángulos que varían entre $42^{\circ}$ a $58^{\circ}$ (Figuras 9A1-9A2). En esta sección se observan fallas menores (fallas D y F), caracterizadas por un rumbo oblicuo y paralelo, respecto de las fallas anteriormente mencionadas y vergencia opuesta (buzamiento al este). Esta deformación coincide con el desarrollo de foliación de rumbo andino.

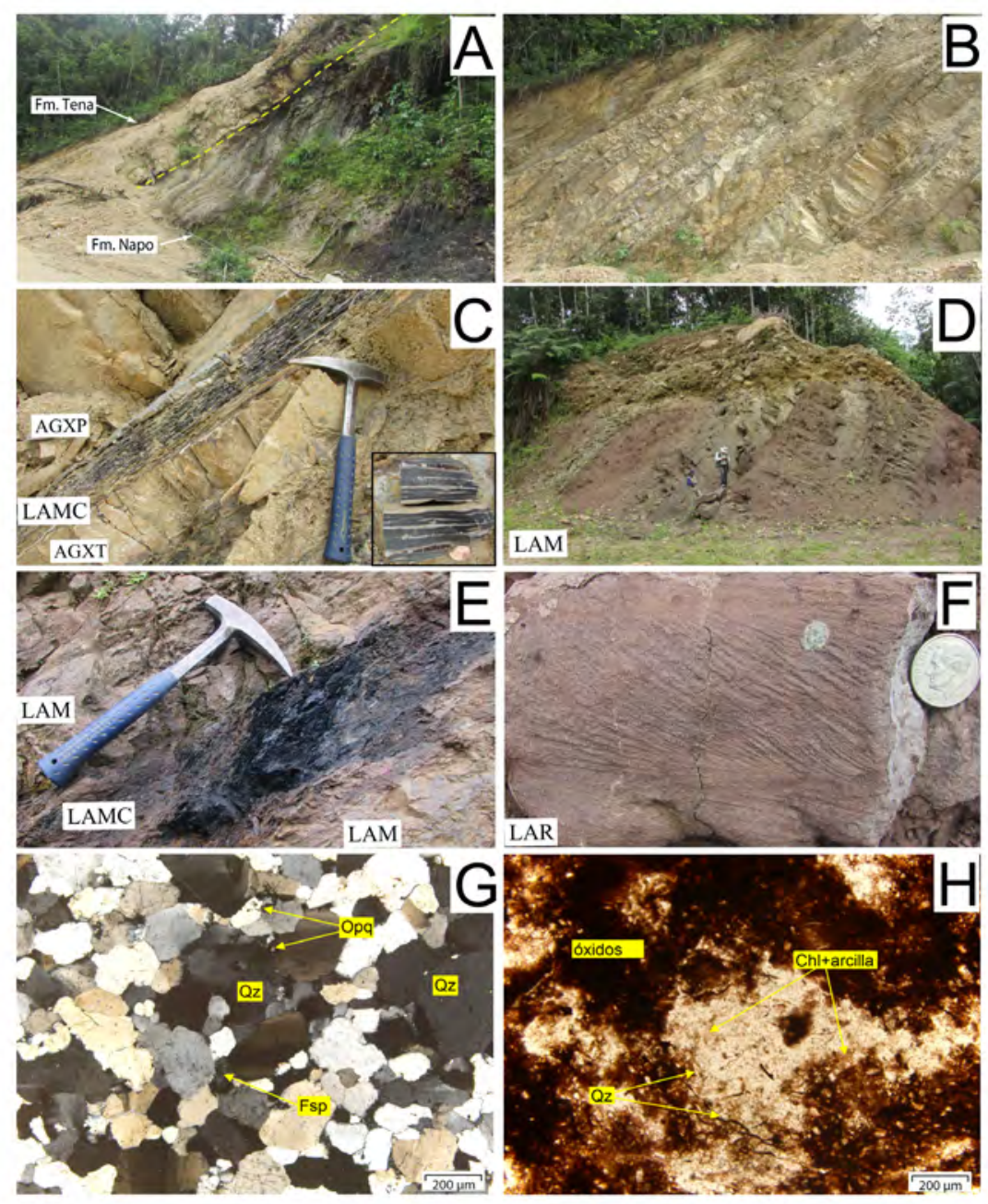

Figura 8. Afloramiento tipo y litofacies de la Formación Tena. A. La Formación Tena cubriendo en discordancia a la Formación Napo. B. Secuencia estratodecreciente de areniscas. C. Lodolitas masivas negras con abundante materia orgánica entre sets de estratos de areniscas con estratificación cruzada. D. Múltiples intercalaciones de limolitas rojas arenosas con areniscas limosas masivas. E. Niveles continuos de materia orgánica y carbón en paquetes de limolitas arenosas masivas. F. Areniscas limosas rojas con ripples y laminación cruzada. G. Sección delgada de arenisca de la Formación Tena en luz polarizada. H. Sección delgada de limolita arenosa de la Formación Tena en luz polarizada.

Zona plegada. Se caracteriza por generar una megaestructura positiva denominada "anticlinal de Miriumi", que afecta a secuencias sedimentarias de las formaciones Hollín, Napo y Tena (Figura 3, Figura 9). Esta sección limita con la FPMC al oeste y con la falla $\mathrm{R}$ al este, formando pliegues cerrados y volcados a diferentes escalas en varios sectores. En el flanco occidental del anticlinal se encuentran la FPMC y las fallas $\mathrm{H}, \mathrm{J}, \mathrm{K}$ y $\mathrm{M}$ (Figura 9), que tienen un rumbo andino casi norte-sur con una vergencia hacia el oeste formando ángulos que varían entre $50^{\circ}$ a $70^{\circ}$; en el flanco oriental del anticlinal, las fallas O, P y R también conservan un rumbo andino, pero se diferencian por su vergencia hacia el este con ángulos que varían entre $45^{\circ}$ a $60^{\circ}$ (Figuras 9B1-9B2). En esta zona se observan fallas menores (fallas I, L, N y Q, en Figura 9), oblicuas 
a las fallas principales con un rumbo noreste a suroeste y vergencia hacia el sureste. El análisis de datos de estratificación presenta tendencia de rumbo andino con un grupo de estratos buzando hacia el este y otro grupo de estratos buzando al oeste, definiendo sus flancos y el eje del pliegue (Figuras 9C1-9C2).

En la zona plegada, los pliegues de arrastre son evidencia de estructuras de cabalgamiento que presentan un rumbo andino con buzamientos fuertes a verticales $\left(60^{\circ}\right.$ a $\left.90^{\circ}\right)$. Localmente, se observa una falla inversa 261/56 (falla J, FC2-27), que afecta a estratos de areniscas de la Formación Tena y estratos de lutitas de la Formación Napo y genera un pliegue de arrastre (Figura 9, Figura 10A). En los flancos del pliegue, los estratos de areniscas intercalados con finas capas de lodolitas y limolitas laminadas ( $\left.\mathrm{S}_{0}: 285 / 44\right)$ definen la secuencia sedimentaria Cretácica-Paleógena (Figura 10B). En la Formación Napo, se evidencian rasgos estructurales en las lutitas negras como micropliegues (Eje: 85/86) y estructuras Riedel (Figuras 10C-10D), mostrando una cinemática inversa.

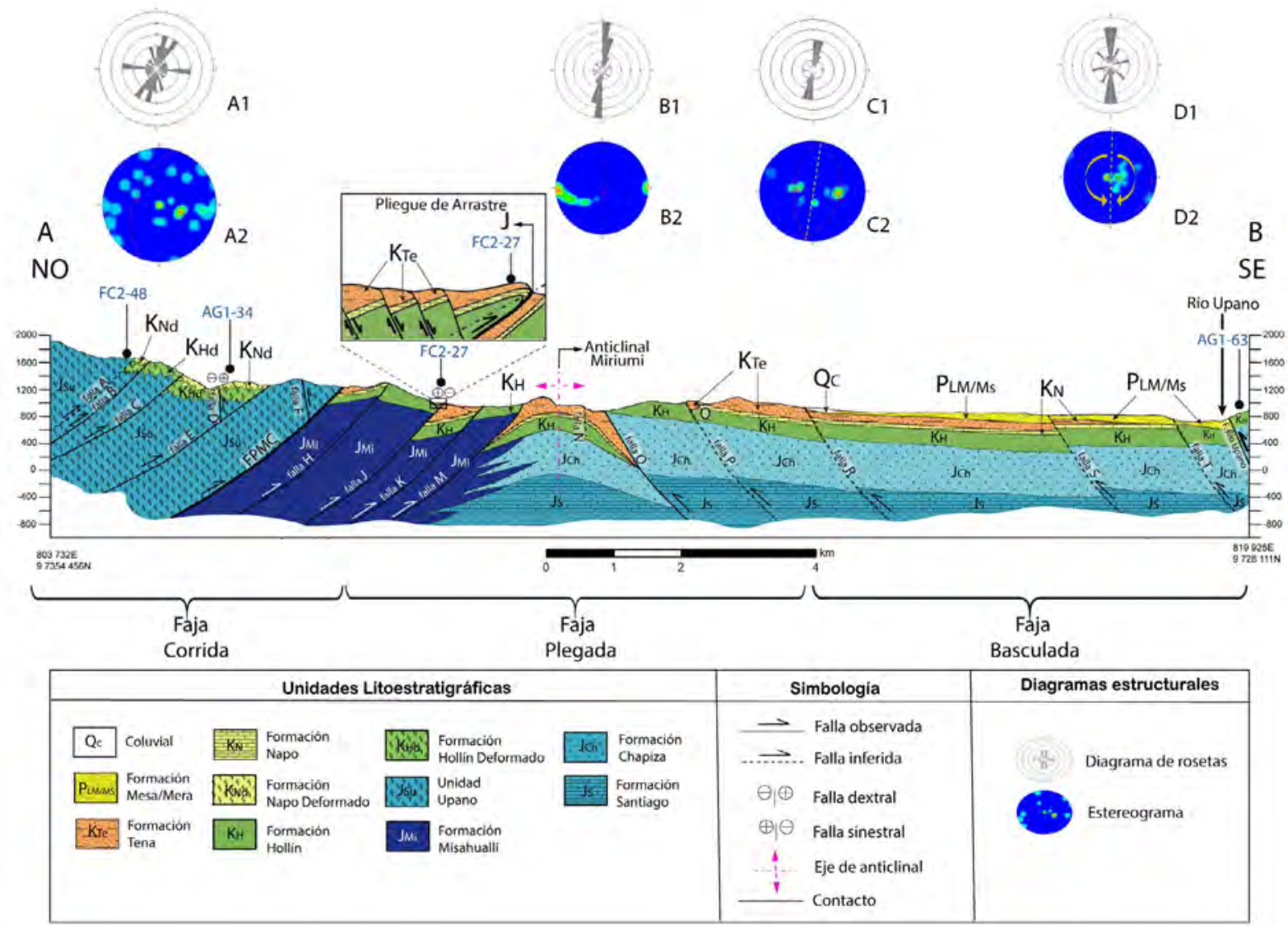

Figura 9. Esquema geológico estructural (NO-SE) interpretado en las formaciones jurásicas, cretácicas, terciarias y cuaternarias presentes en el tramo río Miriumi-río Upano, Sucúa, Morona Santiago.

Zona basculada. Está restringida al este de la zona de estudio y limitada por la falla $\mathrm{R}$ al oeste, se encuentra afectando a las rocas de las formaciones Hollín, Napo, Tena, Mesa/Mera y depósitos cuaternarios. Internamente, se observan bloques delimitados por las fallas R, S, T y por el río Upano con un rumbo andino y vergencia hacia el este, formando ángulos entre $60^{\circ}$ a $80^{\circ}$; estos bloques se encuentran basculados sobre su propio eje (Figuras 9D1-9D2). 


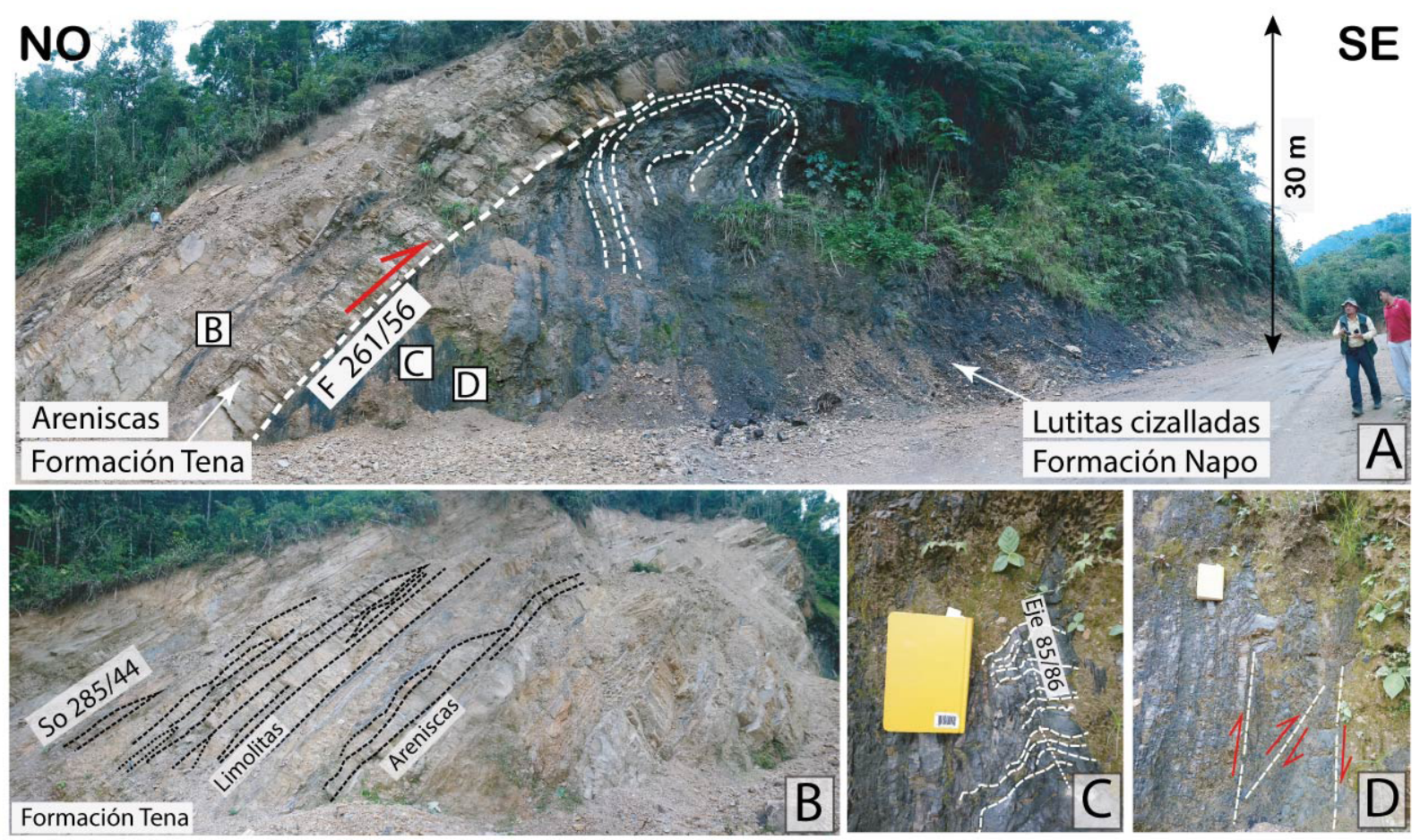

Figura 10. Sección estructural en el sector del río Miriumi, Sucúa, Morona Santiago. Estructuras geológicas menores presentes en las formaciones Napo y Tena. A. Pliegue de arrastre en el sector de Miriumi (UTM: 809 069E, 9 732 932N). B. Arquitectura estratigráfica de la Formación Tena. C. Micropliegues en la Formación Napo. D. Estructura Riedel con cinemática inversa.

\section{Discusión}

A nivel regional, en la sección del río Miriumi, anteriores campañas de cartografía geológica incluyeron dentro de la Unidad Upano segmentos deformados y no deformados de la Cuenca Oriente (INEMIN, 1990; BGS-CODIGEM, 1994), en específico a las formaciones Hollín, Napo y Tena; estos trabajos consideraron a la FPMC como un límite de terreno entre secuencias metamórficas de la Cordillera Real y secuencias sedimentarias de la Cuenca Oriente. En estos no se consideró el registro de estructuras sedimentarias ni la arquitectura estratigráfica de dichas secuencias.

En el presente estudio, siguiendo la descripción inicial de Litherland et al. (1994), en la Unidad Upano se agrupan secuencias volcánicas metamorfoseadas (FMv), que incluyen meta-andesitas, meta-brechas, rocas verdes y esquistos verdes, intercaladas con rocas meta-sedimentarias (FMp), que reúnen principalmente a filitas y cuarcitas deformadas. Se considera que en facies meta-volcánicas las principales características físicas para su identificación son los relictos de textura porfirítica, los fenocristales deformados y las estructuras de remplazamiento en meta-andesitas. La litología y la asociación mineralógica reportada en FMp concuerdan con un protolito sedimentario rico en minerales arcillosos y con proporciones variables de cuarzo (Bucher y Grapes, 2011), relacionado probablemente con argilitas arenosas con abundante materia orgánica (Litherland et al., 1994; Blanco-Quintero et al., 2014). En asociación FMp y FMv se describen secuencias de bajo grado de metamorfismo con facies de sub-esquistos verdes, probablemente relacionadas con la dinámica regional (Pratt et al., 2005).

La Formación Hollín se desarrolla en discordancia angular sobre un basamento heterogéneo (Romero, 2018); en la ZSA se ha reportado previamente el contacto discordante entre la Formación Hollín y 1) el batolito de Zamora (Romero et al., 2019a), 2) la Formación Chapiza (Jaillard et al., 1997; Drobe et al., 2013; Romero, 2018), 3) la Formación Misahuallí (Litherland et al., 1994), 4) el granito Abitagua (Pratt et al., 2005), 5) la Formación Santiago (Baby et al., 2013) y 6) en la zona de estudio la Formación Hollín cubre en discordancia a la Unidad Upano y a las Formaciones Chapiza y Misahuallí. La discordancia angular en la base de la Formación Hollín corresponde a una superficie de erosión de jerarquía regional, 
producto de la deformación del sustrato previo al depósito de la Formación Hollín (Balkwill et al., 1995; White et al., 1995; Jaillard et al., 1997; Pratt et al., 2005; Romero et al., 2019a).

La Formación Hollín puede dividirse en dos miembros; el miembro inferior incluye a conglomerados de cuarzo, cuarzo-areniscas, areniscas limosas. La continuidad lateral de estratos de morfología cóncava-convexa a tabular expresa acreción lateral de canales y barras (Bridge y Lunt, 2006; Parker et al., 2013). No se documentaron facies finas que correspondan a planicies de inundación o depósitos de desbordamiento (Miall, 2014). La amplia gama de estructuras sedimentarias de corriente, tendencias estratodecrecientes y granodecrecientes, indica que el ambiente de depósito del miembro inferior de la Formación Hollín se vincula a sistemas fluviales de ríos trenzados; esta interpretación concuerda con las propuestas por White et al. (1995), Shanmugam et al. (2000) y Romero (2018).

La arquitectura estratigráfica observada en el miembro superior está dominada por estratos tabulares lateralmente continuos y convexos; la amplia gama de estructuras sedimentarias de corriente bimodal documentada (laminación lenticular, flaser, ondulítica, ripples bidireccionales, superficies de reactivación, múltiples intercalaciones rítmicas entre areniscas y limolitas con materia orgánica) indica que el ambiente de depósito del miembro superior de la Formación Hollín está vinculado a ambientes costeros influenciados por mareas (White et al.,1995; Shanmugam et al., 2000; Romero, 2018).

Facies deformadas de la Formación Hollín están relacionadas geográficamente con sistemas de fallas regionales y pueden ser observadas en proximidad a facies no deformadas. En cuarcitas y meta-areniscas se identificaron relictos de laminación cruzada, flaser, ondulítica, lenticular, ripples y figuras ondulíticas deformadas. De acuerdo con estas características, $\mathrm{K}_{\mathrm{HD}}$ expresa bajo grado de metamorfismo, relacionado con estructuras regionales (Bucher y Grapes, 2011).

La interpretación de la Formación Hollín que se presenta en este artículo coincide con White et al. (1995), Shanmugam et al. (2000) y Romero (2018), quienes afirman que el registro estratigráfico de la Formación Hollín marca la transición desde planicies fluviales a ambientes marino costeros influenciados por mareas en el intervalo Aptiano-Albiano en el Cretácico superior.
La Formación Napo agrupa intercalaciones de lutitas calcáreas, calizas y areniscas glauconíticas, con abundante fauna de plataforma marina del Cretácico superior (Jaillard et al., 1997). Es importante considerar que bloques deformados de la Formación Napo (probablemente por la dinámica de las fallas regionales) han sido observados en continuidad a secuencias no deformadas. Al sureste del área de estudio, en las márgenes del río Upano y en el sector de Chinimbini, Jaillard et al. (1997) describen a detalle la Formación Napo (Figura 4B), en donde reportan la presencia de bivalvo Inoceramus sp. y amonite Harleites sp. (?); estas especies han sido identificadas en estratos deformados de la Formación Napo en el río Miriumi.

Sobreyaciendo a la Formación Napo descansa en discordancia la Formación Tena, constituida por intercalaciones de areniscas medias a finas y limolitas multicolores. La arquitectura estratigráfica observada en la Formación Tena es concordante con depósitos de canales aislados entre planicies de inundación; no se identifican figuras de amalgamación lateral. Por otro lado, la abundancia de estructuras sedimentarias de corriente y la tendencia granodecreciente y estratodecreciente, junto con la amalgamación vertical, son comunes en point-bar o barras de punto (Miall, 2014). Facies finas de limolitas arenosas con laminación paralela y ripples de corriente son asociadas a planicies de inundación limosas (Donselaar y Overeem, 2008). Barras de punto aisladas en planicies de inundación son figuras comunes en sistemas aluviales meándricos (Miall, 2014; Romero et al., 2019b).

Tomando en cuenta la dirección de paleocorriente de la Formación Hollín (hacia el noreste) y de la Formación Tena (hacia el este), se puede afirmar que existe un cambio en la posición geográfica de la fuente de detrito, marcada por lo menos desde el Paleoceno. Esta observación coincide con los planteamientos de Ruiz (2002), Vallejo et al. (2017) y Horton (2018), quienes reportan un cambio en la polaridad de sedimentación a finales del Cretácico superior, ubicando al este la posición geográfica de la fuente de detrito y asociando esta secuencia al depósito de sistemas aluviales en el Paleoceno. El hecho de que la fuente de detrito se ubique al este de la zona de estudio implica periodos de exhumación en la Cordillera Real.

Con respecto a la construcción de la Cordillera Real, Litherland et al. (1994) proponen varios periodos de acreción durante su evolución (evento MoromoroTres Lagunas y evento Peltetec). Este modelo implica 
la colisión de múltiples terrenos alóctonos contra la margen continental, razón por la cual se considera a la FPMC como límite de terrenos. En este contexto, se asume a la FPMC como el borde oeste del cratón sudamericano, restringiendo la presencia de rocas de la Cuenca Oriente al oeste de FPMC y considerándola además como una zona de sutura (INEMIN, 1990; Litherland et al., 1994; BGS-CODIGEM, 1994).

Por otro lado, Dashwood y Abbots (1990), Balkwill et al. (1995), Barragán et al. (2005) y Baby et al. (2013) discuten la estructura de la ZSA y proponen la presencia de un sistema de deformación tipo piel gruesa (thickskinned thrust), que estaría relacionado con una zona de desprendimiento intrabasamento que se profundiza bajo la ZSA, incorporando la presencia de una cuña orogénica de empuje. Baby et al. (2013) describen tres dominios tectónicos: el subandino, corredor Sacha Shushufindi y el sistema invertido Capirón Tiputini.

Gutiérrez et al. (2019), en función de consideraciones litoestratigráficas y del análisis de zonas fuentes de detrito (a partir de edades $\mathrm{U} / \mathrm{Pb}$ en circones), plantean la canibalización y exhumación progresiva de los depósitos mesozoicos más occidentales de la Cuenca Oriente, incluyendo las formaciones Hollín y Napo. Los modelos de canibalización de márgenes continentales o cuenca de foreland consideran la generación de sistemas de cabalgamiento a partir de la evolución de pliegues de arrastre a sistemas de corrimientos (Swift y Thorne, 1991; Hodgin et al., 2021); también consideran la incorporación y deformación de secciones de la cuenca de foreland en la orogenia, a partir de múltiples cabalgamientos, y la propagación de la deformación hacia el interior de la margen debido a sistemas de empuje (Sagripanti et al., 2012; Chiocci y Casalbore, 2017). En estos sistemas, la tasa de desplazamiento vertical supera a la tasa de acortamiento horizontal (Brandes y Tanner, 2014).

La sección del río Miriumi es controlada por un sistema de fallas regionales de cinemática inversa, donde se generan fallas de cabalgamiento con un rumbo norte-sur que varía de nor-noreste a sur-suroeste y buzamientos fuertes a verticales $\left(60^{\circ}\right.$ a $\left.90^{\circ}\right)$, lo cual se evidencia en el pliegue de arrastre que se desarrolla entre las formaciones Napo y Tena. También es común la presencia de fallas normales, a partir de las cuales bloques tectónicos son basculados. Estas fallas pueden estar vinculadas a la inversión tectónica de estructuras desarrolladas durante el rift del Jurásico medio a superior (Vallejo et al., 2021).
Datos litoestratigráficos, sedimentológicos y estructurales descartan la interpretación de la FPMC como límite de terreno y concuerdan con los modelos de canibalización de cuencas de foreland. Esta interpretación también coincide con Pratt et al. (2005), quienes reportan la incorporación de bloques de la Cuenca Oriente en el extremo este de la Cordillera Real, en la sección Baños a Puyo, en donde la Formación Margajitas agrupa meta-areniscas y meta-lutitas que cubren en discordancia a la Unidad Upano. Finalmente, Gutiérrez et al. (2019) proponen que la edad de reciclaje o canibalización de secuencias Cretácicas corresponde al intervalo Paleoceno a Eoceno; esta edad se relacionaría también con la incorporación de secuencias Cretácicas de la Cuenca Oriente (formaciones Hollín y Napo) en el orógeno andino.

\section{Conclusiones}

Esta investigación discriminó secuencias sedimentarias y meta-sedimentarias de la Cuenca Oriente, asimiladas en la orogenia andina y anteriormente cartografiadas dentro de la Unidad Upano de la Cordillera Real. Al oeste de la FPMC se identificaron y caracterizaron las formaciones Hollín, Napo y Tena.

En la Unidad Upano se discriminaron y caracterizaron dos facies: rocas meta-volcánicas que incluyen a meta-andesitas porfiríticas con estructuras de reemplazamiento y fenocristales deformados, rocas verdes y meta-brechas silicificadas con fragmentos volcánicos deformados; y las meta-pelitas que incluyen esquistos de illita, calcita, sericita, esquistos de clorita y esquistos sericíticos, y en menor proporción se observan pizarras negras y filitas. En asociación, estas facies describen bajo grado de metamorfismo, facies de sub-esquistos verdes relacionadas con la dinámica regional.

En la Formación Hollín pueden discriminarse dos miembros: el miembro inferior que agrupa secuencias estratodecrecientes compuestas por conglomerados de cuarzo y cuarzo-areniscas con gradación y estratificación cruzada, y el miembro superior que contiene areniscas limosas con laminación flaser, ondulítica, lenticular, ripples bidireccionales, superficies de reactivación y múltiples intercalaciones de limolitas con materia orgánica. En facies deformadas se observan relictos de las estructuras antes mencionadas. La mineralogía de estas facies está dominada por cuarzo, moscovita, en menor proporción illita y materia orgánica. 
La Formación Napo se compone de lutitas negras calcáreas fosilíferas intercaladas entre paquetes de calizas wackstone y packstone y esporádicos niveles de areniscas glauconíticas. Facies deformadas incluyen meta-lutitas, filitas, pizarras con cementación calcárea y calizas masivas recristalizadas en donde se documentaron amonites Inoceramus sp. y Harleites sp. (?). La Formación Napo está cubierta en discordancia angular por la Formación Tena, que incluye areniscas con gradación normal, estratificación cruzada transversal y paralela, intercaladas con areniscas limosas multicolores con laminación paralela, laminación cruzada y ripples de corrientes y limolitas arenosas con materia orgánica.

En la sección del río Miriumi fueron documentados tres estilos de deformación:

- Hacia la cabecera del río Miriumi, al oeste de la FPMC, se observa una zona corrida con buzamientos fuertes, generando corrimientos entre la Unidad Upano y rocas deformadas de las formaciones Hollín y Napo.

- En la parte central del perfil se observa una zona plegada formando un pliegue anticlinal denominado Miriumi y un pliegue de arrastre que afecta a las formaciones Hollín, Napo y Tena.

- $\mathrm{Al}$ este de la zona de estudio, en las proximidades del río Upano, bloques compuestos principalmente por las formaciones Hollín y Napo son afectados por fallas verticales a subverticales generando bloques basculados.

La presencia de bloques y escamas compuestas por secuencias Cretácicas y Paleógenas (formaciones Hollín, Napo y Tena) de la Cuenca Oriente en el frente de la cuña orogénica, afectadas por zonas de corrimiento y pliegues de arrastre, indica que la FPMC no constituye un límite de terreno entre secuencias metamórficas de la Cordillera Real y secuencias sedimentarias de la Cuenca Oriente. Estos datos coinciden con la presencia de una zona de propagación de la deformación en el frente de la cuña orogénica, lo que concuerda con el modelo de canibalización de secuencias de foreland.

\section{Agradecimientos}

Esta investigación fue realizada a partir de la cartografía geológica en el mapa de Sucúa, escala 1:100 000 (IIGE, 2019), realizada en el proyecto "Investigación Geológica y Disponibilidad de Ocurrencias Minerales en el Territorio Ecuatoriano", desarrollado por el Instituto de Investigación Geológico y Energético del Ecuador (IIGE). Un agradecimiento especial a Bernardo Beate, catedrático de la Escuela Politécnica Nacional, por su valiosa contribución y apoyo profesional en la realización de esta investigación.

\section{Referencias}

Aspden, J.A.; Litherland, M. (1992). The geology and Mesozoic collisional history of the Cordillera Real, Ecuador. Tectonophysics, 205(1-3), 187-204. https://doi.org/10.1016/0040-1951(92)90426-7

Baby, P.; Rivadeneira, M.; Barragán, R.; Christophoul, F. (2013). Thick-skinned tectonics in the Oriente foreland basin of Ecuador. Geological Society, London, Special Publications, 377, 59-76. https:// doi.org/10.1144/SP377.1

Balkwill, H.R.; Rodriguez, G.; Paredes, F.I.; Almeida, J.P. (1995). Northern part of Oriente Basin, Ecuador: reflection seismic expression of structures. In: A.J. Tankard, R. Suarez, H.J. Welsink (eds). Petroleum basins of South America (pp. 559-571). AAPG Memoir, vol. 62. https:// doi.org/10.1306/M62593C29

Barragán, R.; Baby, P.; Duncan, R. (2005). Cretaceous alkaline intra-plate magmatism in the Ecuadorian Oriente Basin: Geochemical, geochronological and tectonic evidence. Earth and Planetary Science Letters, 236(3-4), 670-690. https://doi. org/10.1016/j.epsl.2005.03.016

BGS-CODIGEM. (1994). Geological and metal ocurrence maps of the Cordillera Real and El Oro metamorphic belts, Ecuador.

Blanco-Quintero, I.F.; García-Casco, A.; Toro, L.M.; Moreno, M.; Ruiz, E.C.; Vinasco, C.J.; Cardona, A.; Lázaro, C.; Morata, D. (2014). Late Jurassic terrane collision in the northwestern margin of Gondwana (Cajamarca Complex, eastern flank of the Central Cordillera, Colombia). International Geology Review, 56(15), 1852-1872. https://doi. org/10.1080/00206814.2014.963710

Brandes, C; Tanner, D. (2014). Fault-related foling: A review of kinematic models and their application. Earth Science Reviews, 138, 352-370. https://doi. org/10.1016/j.earscirev.2014.06.008 
Bridge, J.S.; Lunt, I.A. (2006). Depositional models of braided rivers. In: G.H. Sambrook-Smith, J.L. Best, C.S. Bristow, G.E. Petts (eds.). Braided Rivers: Processes, Deposits, Ecology and Management (pp. 11-49). Blackwell Publishing Ltd. https://doi.org/10.1002/9781444304374.ch2

Bucher, K.; Grapes, R. (2011). Petrogenesis of metamorphic rocks. Springer.

Chiocci, F.L.; Casalbore, D. (2017). Unexpected fast rate of morphological evolution of geologicallyactive continental margins during Quaternary: Examples from selected areas in the Italian seas. Marine and Petroleum Geology, 82, 154-162. https://doi.org/10.1016/j.marpetgeo.2017.01.025

Dashwood, M.; Abbotts, I. (1990). Aspects of the petroleum geology of the Oriente basin, Ecuador. Geological Society, London, Special Publications, 50, 89-117. https://doi.org/10.1144/ GSL.SP.1990.050.01.06

Donselaar, M.E.; Overeem, I. (2008). Connectivity of fluvial point-bar deposits: An example from the Miocene Huesca fluvial fan, Ebro Basin, Spain. AAPG Bulletin, 92(9), 1109-1129. https://doi. org/10.1306/04180807079

Drobe, J.; Lindsay, D.; Stein, H.; Gabites, J. (2013). Geology, mineralization, and geochronological constraints of the Mirador Cu-Au porphyry district, southeast Ecuador. Economic Geology, 108(1), 11-35. https://doi.org/10.2113/econgeo.108.1.11

Gaibor, J.; Hochuli, J.P.; Winkler, W.; Toro, J. (2008). Hydrocarbon source potential of the Santiago formation, Oriente basin, SE of Ecuador. Journal of South American Earth Sciences, 25(2), 145-156. https://doi.org/10.1016/j.jsames.2007.07.002

Gutiérrez, E.G.; Horton, B.K.; Vallejo, C.; Jackson, L.J.; George, S.W. (2019). Provenance and geochronological insights into Late CretaceousCenozoic foreland basin development in the Subandean Zone and Oriente Basin of Ecuador. In: B.K. Horton, A. Folguera (eds.). Andean Tectonics (pp. 237-268). Elsevier. https://doi. org/10.1016/B978-0-12-816009-1.00011-3

Hodgin, E.B.; Gutiérrez-Marco, J.C.; Colmenar, J.; Macdonald, F.A.; Carlotto, V.; Crowley, J. L.; Newmann, J.R. (2021). Cannibalization of a late
Cambrian backarc in southern Peru: New insights into the assembly of southwestern Gondwana. Gondwana Research, 92, 202-227. https://doi. org/10.1016/j.gr.2021.01.004

Horton, B.K. (2018). Sedimentary record of Andean mountain building. Earth-Science Reviews, 178, 279-309. https://doi.org/10.1016/j. earscirev.2017.11.025

INIGEMM (2017). Mapa geológico de la República del Ecuador escala 1:1 000 000. Instituto Nacional de Investigación Geológico Minero Metalúrgico (INIGEMM), Quito-Ecuador.

IIGE (2019). Memoria técnica del mapa geológico de Sucúa, escala 1: 100 000. IIGE, Ecuador. Informe inédito.

INEMIN (1990). Mapa geológico de Sucúa, escala 1:100.000, hoja 91. INEMIN, Ecuador.

Jaillard, E.; Caron, M.; Dhondt, A.; Ordoñez, M.; Lascano, M.; Andrade, R.; Bengtson, P.; Bulot, L.; Cappetta, H.; Dávila, C.; Díaz, R.; Huacho, J.; Huamán, C.; Jiménez, D.; Jiménez, N.; Montenegro, J.; Néraudeau, D.; Rivadeneira, M.; Toro, J.; Villagómez, R.; Zambrano, Í. (1997). Síntesis estratigráfica y sedimentológica del Cretáceo y Paleógeno de la Cuenca Oriental del Ecuador. Convenio ORSTOMPETROPRODUCCION.

Jaillard, E.; Lapierre, H.; Ordoñez, M.; Toro, J.; Amórtegui, A.; Vanmelle, J. (2009). Accreted oceanic terranes in Ecuador: southern Edge of the Caribean Plate? Geological Society, London, Special Publications, 328, 469-485. https://doi. org/10.1144/SP328.19

James, N.P.; Dalrymple, R.W. (2010). Fácies models 4. St. John's, Nfld.: Geological Association of Canada.

Litherland, M.; Aspden, J.A.; Jemielita, R.A. (1994). The metamorphic belts of Ecuador. Overseas Geology and Mineral Resources, 11. 2 map enclosures at 1:500,000 scale. British Geological Survey. https://doi.org/10.1017/ S0016756897297657

Miall, A. (2014). The facies and architecture of fluvial systems. In: Fluvial depositional 
systems (pp. 9-68). Springer, Cham. https://doi. org/10.1007/978-3-319-00666-6_2

Parker, N.O.; Sambrook-Smith, G.H.; Ashworth, P.J.; Best, J.L.; Lane, S.N.; Lunt, I.A.; Simpson, C.J.; Thomas, R.E. (2013). Quantification of the relationship between surface morphodynamics and subsurface sedimentological product in sandy braided rivers. Sedimentology, 60(3), 820-839. https://doi.org/10.1111/j.13653091.2012.01364.x

Petit, J.P. (1987). Criteria for the sense of movement on fault surfaces in brittle rocks. Journal of Structural Geology, 9(5-6), 597-608. https://doi. org/10.1016/0191-8141(87)90145-3

Pratt, W.T.; Duque, P.; Ponce, M. (2005). An autochthonous geological model for the eastern Andes of Ecuador. Tectonophysics, 399(1-4), 251278. https://doi.org/10.1016/j.tecto.2004.12.025

Romero, C. (2018). Identificación y caracterización de facies de la formación Hollín en el Centro Shaime: el registro de una transición fluvio-marina en la región sur oriental del Ecuador. Tesis, Escuela Politécnica Nacional, Ecuador.

Romero, C.W.; Gramal, A.B.; Carranco, F.R.; Toainga, S.D. (2019a). Asociación de facies: La clave para la identificación de la Formación Hollín en la región sur oriental del Ecuador. Revista Científica GeoLatitud, 2(1), 9-23.

Romero, C.W.; Calderón, E.D.; Ribadeneira, M.V.; Naranjo, M.E.; Meneses, V.M.; Gramal, A.B. (2019b). Reconstruyendo el pasado del planeta: El registro estratigráfico y sedimentológico de la Formación Tena en la carretera Tiwintza-Puerto Morona. Revista Cientifica GeoLatitud, 2(2), 2-13.

Ruiz, G.M.H. (2002). Exhumation of the northern subAndean zone of Ecuador and source regions: A combined thermochronological and heavy mineral approach. Doctoral dissertation, ETH Zurich, Zurich, Switzerlnad. https://doi.org/10.3929/ ethz-a-004489528

Ruiz, G.M.H.; Seward, D.; Winkler, W. (2004). Detrital thermochronology - a new perspective on hinterland tectonics, an example from the Andean amazon basin, Ecuador. Basin Research, 16(3),
413-430. https://doi.org/10.1111/j.13652117.2004.00239.x

Ruiz, G.M.; Seward, D.; Winkler, W. (2007). Evolution of the Amazon Basin in Ecuador with special reference to hinterland tectonics: data from zircon fission-track and heavy mineral analysis. Developments in Sedimentology, 58, 907-934. https://doi.org/10.1016/S0070-4571(07)58036-2

Sagripanti, L.; Bottesi, G.; Kietzmann, D.; Folguera, A.; Ramos, V.A. (2012). Mountain building processes at the orogenic front. A study of the unroofing in Neogene foreland sequence $\left(37^{\circ} \mathrm{S}\right)$. Andean Geology, 39(2), 201-219. https://doi. org/10.5027/andgeoV39n2-a01

Shanmugam, G.; Poffenberger, M.; Toro Alava, J. (2000). Tide-dominated estuarine facies in the Hollin and Napo (“T” and "U”) formations (Cretaceous), Sacha field, Oriente basin, Ecuador. AAPG Bulletin, 84(5), 652-682. https:// doi.org/10.1306/C9EBCE7D-1735-11D7$8645000102 \mathrm{C} 1865 \mathrm{D}$

Spikings, R.A.; Winkler, W.; Seward, D.; Handler, R. (2001). Along strike variations in the thermal and tectonic response of the continental Ecuadorian Andes to the collision with heterogeneous oceanic crust. Earth and Planetary Science Letters, 186(1), 57-73. https://doi.org/10.1016/S0012821X(01)00225-4

Spikings, R.; Cochrane, R.; Villagomez, D.; Van der Lelij, R.; Vallejo, C.; Winkler, W.; Beate, B. (2015). The geological history of northwestern South America: from Pangaea to the early collision of the Caribbean Large Igneous Province (290-75 Ma). Gondwana Research, 27(1), 95139. https://doi.org/10.1016/j.gr.2014.06.004

Spikings, R.; Paul, A.; Vallejo, C.; Reyes, P. (2021). Constraints on the ages of the crystalline basement and Palaeozoic cover exposed in the Cordillera real, Ecuador: ${ }^{40} \mathrm{Ar} /{ }^{39} \mathrm{Ar}$ analyses and detrital zirco U/Pb geochronology. Godwana Research, 90, 77101. https://doi.org/10.1016/j.gr.2020.10.009

Swift, D.J.P.; Thorne, J.A. (1991). Sedimentation on continental margins, I: a general model for shelf sedimentation. In: D.J.P. Swift, G.F. Oertel, R.W. Tillman, J.A. Thorne (eds.). Shelf Sand and Sandstone Bodies: Geometry, 
Facies and Sequence Stratigraphy (pp. 1-31). Blackwell Scientific Publications. https://doi. org/10.1002/9781444303933.ch1

Tschopp, H.J. (1953). Oil explorations in the Oriente of Ecuador, 1938-1950. AAPG Bulletin, 37(10), 2303-2347. https://doi.org/10.1306/5CEADD9416BB-11D7-8645000102C1865D

Vallejo, C.; Winkler, W.; Spikings, R.A.; Luzieux, L.; Heller, F.; Bussy, F. (2009). Mode and timing of terrane accretion in the forearc of the Andes in Ecuador. In: S.M. Kay, V.A. Ramos, W.R. Dickinson (eds.). Backbone of the Americas: shallow subduction, plateau uplift, and ridge and terrane collision (pp. 197-216). Geological Society of America. https://doi. org/10.1130/2009.1204(09)

Vallejo, C.; Tapia, D.; Gaibor, J.; Steel, R.; Cardenas, M.; Winkler, W.; Valdez, A.; Esteban, J.; Figuera, M.; Leal, J.; Cuenca, D. (2017). Geology of the Campanian M1 sandstone oil reservoir of eastern Ecuador: a delta system sourced from the Amazon Craton. Marine and Petroleum Geology, 86, 1207-1223. https://doi.org/10.1016/j. marpetgeo.2017.07.022

Vallejo, C.; Spikings, R.A.; Horton, B.K.; Luzieux, L.; Romero, C.; Winkler, W.; Thomsen, T.B. (2019). Late Cretaceous to Miocene stratigraphy and provenance of the coastal forearc and Western Cordillera of Ecuador: Evidence for accretion of a single oceanic plateau fragment. In: B.K. Horton, A. Folguera (eds.). Andean Tectonics (pp. 209236). Elsevier. https://doi.org/10.1016/B978-012-816009-1.00010-1

Vallejo, C.; Romero, C.; Horton, B.; Spikings, R.; Gaibor, J.; Winkler, W.; Esteban, J.; Thomsen, T.; Mariño E. (2021). Jurassic to Early Paleogene sedimentation in the Amazon region of Ecuador: Implications for the paleographic evolution of northwestern South America. Global and Planetary Change, 204. https://doi.org/10.1016/j. gloplacha.2021.103555

Walker, R.G. (1990). Facies modeling and sequence stratigraphy. Journal of Sedimentary Research, 60(5), 777-786. https://doi.org/10.1306/212F926E2B24-11D7-8648000102C1865D

White, H.J.; Skopec, R.A.; Ramírez, F.A.; Rodas, J.A.; Bonilla, G. (1995). Reservoir characterization of the Hollin and Napo formations, Western Oriente Basin, Ecuador. In: A.J. Tankard, R. Suarez, H.J. Welsink (eds.). Petroleum Basins of South America (pp. 573-596). AAPG Memoir, Vol. 62. https://doi.org/10.1306/M62593C30

Fecha de recibido: 27 de octubre de 2020 Fecha de aprobado: 14 de septiembre de 2021 